Review

\title{
Current Status of Older and New Purine Nucleoside Analogues in the Treatment of Lymphoproliferative Diseases
}

\author{
Tadeusz Robak *, Anna Korycka, Ewa Lech-Maranda and Pawel Robak
}

Department of Hematology, Medical University of Lodz and Copernicus Memorial Hospital, 93-510 Lodz, Ciolkowskiego 2 Str., Poland

* Author to whom correspondence should be addressed. E-mail: robaktad@csk.umed.lodz.pl; Tel.: +48 42 689-51-91; Fax: + 4842 689-51-92.

Received: 6 January 2009; in revised form: 27 February 2009 / Accepted: 10 March 2009 / Published: 23 March 2009

\begin{abstract}
For the past few years more and more new cytotoxic agents active in the treatment of hematological malignancies have been synthesized and become available for either in vitro studies or clinical trials. Among them the class of antineoplastic drugs belonging to the purine nucleoside analogues group (PNAs) plays an important role. Three of them: pentostatin (DCF), cladribine (2-CdA) and fludarabine (FA) were approved by Food and Drug Administration (FDA) for the treatment of hematological malignancies. Recently three novel PNAs: clofarabine (CAFdA), nelarabine (ara-G) and forodesine (immucillin $\mathrm{H}, \mathrm{BCX}-1777$ ) have been synthesized and introduced into preclinical studies and clinical trials. These agents seem to be useful mainly for the treatment of human T-cell proliferative disorders and they are currently undergoing clinical trials in lymphoid malignancies. However, there are also several studies suggesting the role of these drugs in B-cell malignancies. This review will summarize current knowledge concerning the mechanism of action, pharmacologic properties, clinical activity and toxicity of PNAs accepted for use in clinical practice, as well as new agents available for clinical trials.
\end{abstract}

Keywords: Fludarabine; Cladribine; Pentostatin; Clofarabine; Nelarabine; Forodesine; Purine nucleoside analogues; Mechanism of action; Clinical application. 


\section{Contents}

1. Introduction

2. Pharmacology and mechanism of action

3. Clinical activity

4. Side effects and tolerability

5. Conclusions

\section{Introduction}

Over the past few years more and more new cytotoxic agents active in the treatment of hematological malignancies have been synthesized and become available for either in vitro studies or clinical trials. Among them the class of antineoplastic drugs belonging to the group of purine nucleoside analogues (PNAs) plays an important role [1,2]. In the 80-90s of the last century three of them were approved by Food and Drug Administration (FDA) for the treatment of hematological malignancies. Fludarabine (2-fluoro-9-( $\beta$-D-arabinofuranosyl)-adenine; FA), cladribine (2-chloro-9(2'-deoxy- $\beta$-D-ribofuranosyl)adenine; 6-amino-2-chloro-9-( $\beta$-D-erythro-pentofuranosyl) purine, 2 chloro-2'-deoxyadenosine; 2-CdA) and pentostatin (2'-deoxycoformycin, (8R)-3-(2-deoxy- $\beta$-Derythro-pentofuranosyl)-3,4,7,8-tetrahydroimidazo [4,5-d] [1,3] diazepin-8-ol, DCF) have chemical structures similar to adenosine or deoxyadenosine (Figure 1). Limited solubility of FA and difficulties in its formulation led to the synthesis of the FA prodrug - fludarabine 5'-monophosphate (FA-MP) which is commercially available.

Figure 1. Structures of older nucleoside analogues: cladribine, fludarabine and pentostatin.<smiles>Nc1nc(Cl)nc2c1ncn2C1CC(O)C(CO)O1</smiles>

Cladribine

2-chloro-9-(2'-deoxy- $\beta$-D-ribofuranosyl)adenine (2-CdA)<smiles></smiles>

Fludarabine

2-fluoro-9-( $\beta$-Darabinofuranosyl)-adenine (FA)<smiles>OCC1OC2CNC=Nc3c1ncn3CC(O)C(O)C2</smiles>

Pentostatin

2'-deoxycoformycin (DCF)

The structure of 2-CdA differs from the naturally occurring nucleoside in the substitution of hydrogen by chlorine at the 2-position of the adenine ring. FA is a halogenated analog of 
arabinofuranosyladenine with fluorine at the 2-position of the adenine ring, whereas DCF is a product of fermentation cultures of Streptomyces antibioticus or Aspergillus nidulans. All three PNAs share many other similar characteristics such as uptake into the cells via nucleoside transporters, phosporylation by deoxycytidine kinase (dCK) and dephosphorylation by 5 '-nucleosidase (5'-NT) $[3,4]$. Although all three PNAs have a similar chemical structure and act mainly by induction of apoptosis, they show different efficacy against hematological malignancies and they exhibit significant differences, especially concerning their interactions with enzymes involved in adenosine or deoxyadenosine metabolism [5,6].

Several clinical trials have demonstrated that these drugs, used either alone or in combination with other cytotoxic agents or monoclonal antibodies, show good efficacy and acceptable toxicity profile in the treatment of indolent lymphoid malignancies [5,6]. DCF and 2-CdA are currently the drugs of choice in hairy cell leukemia (HCL) [7]. FA and 2-CdA alone or in combination with other agents are highly effective in chronic lymphocytic leukemia (CLL) and low grade B- and T-cell non-Hodgkin's lymphomas (NHL) [8-11]. FA and 2-CdA showed also effectiveness in patients with Waldenström Macroglobulinemia (WM) and cutaneous T-cell lymphoma (CTCL) [12-14].

Recently three novel PNAs: clofarabine 2-chloro-9-(2'-deoxy-2'-fluoro- $\beta$-D-arabinofuranosyl) adenine; CAFdA), nelarabine [6-methoxy-9-( $\beta$-D-arabinofuranosyl) guanine; 2-amino-6-methoxy-9( $\beta$-D-arabinofuranosyl) purine, pro ara-G] and forodesine $\{7$-(3,4-dihydroxy-5-hydroxymethyl-pyrrolidyn-2-yl)-3,5-dihydropyrrolo [3,2-d] pyrimidin-4-one; immucillin $\mathrm{H}, \mathrm{BCX}-1777\}$ have been synthesized and introduced into in vitro studies and clinical trials (Figure 2) [15]. CAFdA, like 2-CdA, is a deoxyadenosine analogue and exhibits efficacy in both acute myeloblastic leukemia (AML) and acute lymphoblastic leukemia (ALL), blast crisis of chronic myelogenous leukemia (CML-BP) and myelodysplastic syndrome (MDS) [16-18]. This agent is also active in pediatric patients with advanced leukemias.

Figure 2. Structures of new nucleoside analogues: nelarabine, forodesine and clofarabine.<smiles>COc1nc(N)nc2c1ncn2C1OC2OC1C(CO)C2O</smiles>

Nelarabine

6-metoksy-9-( $\beta$-Darabinofuranosyl) guanine (pro ara-G)<smiles></smiles>

Forodesine

7-(3,4-dihydroxy-5hydroxymethylopyrrolidyn-2yl)-3,5-dihydropyrrolo [3,2-d] pyrimidin-4-one (BCX-1777, immucillin H)<smiles>Nc1nc(Cl)nc2c1ncn2C1OC2OCC1C2O</smiles>

Clofarabine

2-chloro-9-(2'-deoxy-2'fluoro- $\beta$-D-arabinofuranosyl)adenine (CAFdA) 
Nelarabine is a water-soluble prodrug of $9-\beta$-D-arabinofuranosylguanine (ara-G), which is its active metabolite [19-21]. Ara-G is selectively toxic to mature T-cells and immature T-lymphoblasts as compared to B-lymphoblasts or null-cells which are resistant to ara-G.

Forodesine belongs to a class of 9-deazanucleoside analogues which are purine nucleoside phosphorylase (PNP) inhibitors, termed immucillins [22,23]. This agent shows activity in some experimental tumors in mice. It could be useful for the treatment of human T-cell proliferative disorders and it is currently undergoing clinical trials for the treatment of T-cell NHL, which includes CTCL and T-cell ALL. However, recently forodesine seems to be useful also in the treatment of B-cell NHL and the great hopes are set on the use of the drug in B-CLL.

This review article summarizes current knowledge about mechanism of action, pharmacokinetics, pharmacological properties, clinical activity and toxicity of older and new PNAs.

\section{Pharmacology and Mechanism of Action}

As it was mention above, the PNAs share several similar characteristics including transportation into the cells, phosphorylation to monophosphates by cytosolic dCK or mitochondrial deoxyguanosine kinase (dGK) and dephosphorylation by 5'-NT. However, there are also PNAs such as nelarabine, forodesine, pentostatin which do not need to be phosphorylated and they exhibit significant individual differences in their interaction with enzymes involved in the purine metabolism. On the other hand, all the PNAs are characterized by a similar mechanism of cytotoxicity both in proliferating and quiescent cells, such as inhibition of DNA synthesis, inhibition of DNA repair and accumulation of DNA strand breaks $[5,6]$. The main role in the mechanism of PNA activity plays induction of apoptosis which is the end-point of their action. This proces takes place mainly through the intristic pathway, via modulation of P53 expression or directly via binding to proteins located in mitochondrial membrane, leading to changes in mitochondrial membrane permeability.

The first step of the cellular activity of PNA, is their uptake into the cells which occurs via at least nine different nucleoside transporter (NT) systems, which may significantly modulate intracellular drug bioavailability and responsiveness to therapy. Over the last decades two families of human NT (human equilibrative nucleside transporters; hENT and human concentrative nucleoside transporters; hCNT) have been identified and extensively studied [8,24,25]. Four of NT belonging to hENT family are sodium-independent-facilitated system and transport nucleosides down the concentration gradient . Five other hCNT are sodium - dependent system and can transport nucleosides against a concentration gradient [24]. Additionaly, ABCG2 (breast cancer resistance protein), like a first transporter directly linked to the efflux of nucleoside monophosphate analogues from mammalian cells-MRP4 (multidrug resistance protein), transport and confer resistance to PNA. These two transporeters work in parallel to affect drug cytotoxicity and tissue distribution [26]. The single - nucleotide polymorphism in human MRP4 dramatically reduces MRP4 function by impairing its cell membrane localization [27].

\subsection{Fludarabine}

FA, like other PNAs, permeates the cell via different NT systems. However, NT accept only dephosphorylated forms, so prior to entering the cell, commercially available FA-MP is rapidly 
dephosphorylated in plasma to FA by ecto-5' -NT. FA can be transported into the cells via such NT as hENT1, hENT2, hCNT2, hCNT3 (Figure 3) [24,28-30]. After the uptake into the cells, FA must be converted by $\mathrm{dCK}$ or $\mathrm{dGK}$ into its triphosphate form, which is the active metabolite required for its cytotoxicity [31]. At the same time the phosphorylated metabolite is dephosphotylated by 5'-NT. In lymphoid cells, a high ratio of $\mathrm{dCK} / 5^{\prime}$-NT activity favors the accumulation of phosphorylated metabolites which inhibit various processes involved in DNA and RNA synthesis, modulate apoptosis, influence cell-cycle control or signal transduction pathways [32].

Figure 3. Mechanism of 2-CdA and FA action.

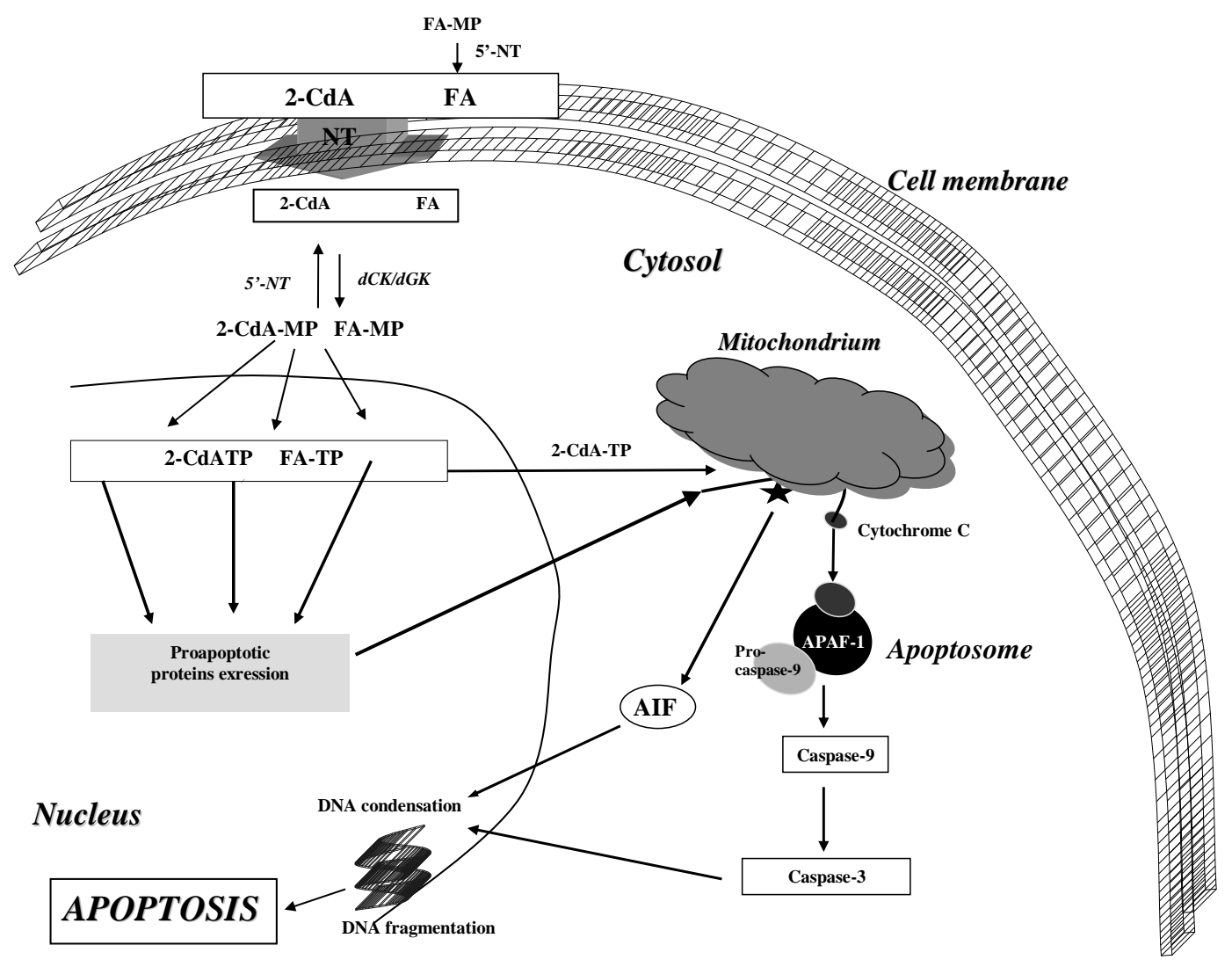

2-CdA-2-chloro-2'-deoxyadenosine; FA-MP-fludarabine monophosphate; FAfludarabine; 2-CdA-MP-2-CdA monophosphate; FA-TP-fludarabine triphosphate; 2CdA-TP-2-CdA-triphosphate; NT-nucleoside transporter; 5'-NT-5'-nucleotidase; dCKdeoxycytidine kinase; AIF-apoptosis-inducing factor; APAF-1-apoptotic protease activating factor;

FA-MP is converted to FA by an apparent first-pass metabolism within five minutes after rapid intravenous (i.v.) infusion and linear relationship between the dose of FA-MP and FA concentration was observed [33]. Peak intracellular levels of FA-TP, an active metabolite of FA were observed within 3-4 hours after termination of FA-MP infusion. Plasma concentrations of FA were fitted to a three-compartment open model. The half-life $\left(\mathrm{T}_{1 / 2} \alpha\right)$ was five minutes, followed by an intermediate phase $\left(T_{1 / 2} \beta\right)$ of 1.38 hours and a prolonged terminal phase $\left(T_{1 / 2} \gamma\right)$ of 10.41 hours. The mean apparent value of distribution (Vdr) was $62.28 \pm 16.88 \mathrm{~L} / \mathrm{m}^{2}$, and the mean steady-state volume of distribution (Vdss) was $44.17 \pm 10.82 \mathrm{~L} / \mathrm{m}^{2}$. Since Vdr is greater than Vdss, these data indicate extensive tissue 
binding of FA [34]. FA is eliminated from the body in the urine as approximately $60 \%$ of this drug is present in the urine within 24 hours of administration. Total body clearance of FA $\left(67.98 \mathrm{~mL} / \mathrm{min} / \mathrm{m}^{2} \pm\right.$ 19.58) correlates with creatinine clearance [30]. FA-MP is usually administered at a dose of 25 $\mathrm{mg} / \mathrm{m}^{2} /$ day in a $30 \mathrm{~min}$ infusion or i.v. bolus injection for 3-5 days and the courses are repeated every 3-5 weeks [33,35].

An oral formulation of FA-MP has recently become commercially available. Biovailability of oral FA-MP is about $50 \%$ to $75 \%$ of the i.v. dose with a similar terminal $\mathrm{T}_{1 / 2}$, and is unaffected by food [1, 36]. It has been recently reported that an oral dose of approximately $40-50 \mathrm{mg} / \mathrm{m}^{2}$ /day of FA-MP provids systemic exposure equivalent to $25 \mathrm{mg} / \mathrm{m}^{2} /$ day of routinely given i.v. [33]. The oral formulation of FA-MP is easier to use and can be administered on an out-patient basis [37].

\subsection{Cladribine}

Intracellular phosphorylation of 2-CdA (2-chloro-9-(2'-deoxy- $\beta$-D-ribofuranosyl)-adenine;2-chloro2 '-deoxyadenosine) is necessary for any cytostatic effects to occur. Like FA, it is phosphorylated by $\mathrm{dCK}$ and accumulated as 2-chlorodeoxyadenosine triphosphate (2-CdA-TP) [38]. The nucleotide that is formed does not readily exit from the cells through the cell membrane and therefore accumulates inside the cell. This metabolite disrupts cell metabolism by incorporating into the DNA of the actively dividing cells and freezes cell cycle at $\mathrm{S}$ phase [38,39]. The uptake of this drug into the cells is also mediated through one or more of NT and may significantly modulate intracellular drug bioavailability and, consequently, responsiveness to therapy. The drug is transported via hENT1, hENT2, hCNT2, hCNT3 [24]. ABCG2 transports and confers resistance to cladribine and interact with this drug by a site distinct from the prazosin binding site as shown by their inability to displace the substrate analogue [26]

In contrast to other antineoplastic drugs, but similarly to other PNA, 2-CdA is cytotoxic to both proliferating and quiescent cells. Several pathways are suggested to be responsible for the mechanism of their action. The cytotoxicity of 2-CdA in the proliferating cells is mainly due to either suppression of DNA synthesis via inhibition of DNA polymerases, or incorporation into DNA, or inhibition of DNA repair and accumulation of DNA breaks. In addition, 2-CdA strongly inhibits ribonucleotide reductase (RR) activity leading to imbalance in deoxynucleotide triphosphates (dNTP) pool, and via endonuclease activation leads to DNA strand breaks [40,41]. It is also suggested that the cytotoxic mechanism of 2-CdA may originate not only from the suppression of RR and DNA polymerases, but also from the inhibition of deoxyadenosine deamination and phosphorylation, with subsequent inactivation of 5-adenosylhomocysteine hydrolase (SAHM) as a natural consequence of adenosine accumulation [42]. It is also known that RR and two other enzymes: 5'-NT and PNP participate in catalysing purine nucleoside degradation [43]. DNA breaks activate poly(ADP-ribose) polymerase (PARP), leading to nicotinamide adenine dinucleoside (NAD) and adenosine triphosphate (ATP) depletion and can kill cell along the necrosis pathway [1]. On the other hand, DNA damage induces P53 expression and eventually leads to apoptosis which is the main mechanism of 2-CdA cytotoxicity. Recently, it has been found that P53 may also contribute to cytotoxicity in dividing cells by binding to DNA with incorporated 2-CdA as P53/DNA-PK complex [44]. In quiescent cells 2-CdA-TP interferes with proper repair of DNA and leads to a total disruption of cellular metabolism via accumulation of 
breaks in DNA strand, which in turn leads to P53 expression and consequently to induction of apoptosis [8]. In these cells, however, both P53-dependent and P53-independent cytotoxicity mechanisms are suggested to occur $[45,46]$.

Apoptosis induced by 2-CdA can be mediated either via DNA damage and P53 protein expression or directly via mitochondrial permeability transition pores (mtPTP) [43]. Inhibition of DNA repair and accumulation of DNA breaks leads to P53 expression which plays a key role in the control of apoptosis and cell cycle and influences the BCL-2 protein family with antiapoptotic properties as well as BCL-2 like proteins such as BAX, BCL-xs and BAK which have proapoptotic action $[47,48]$. The most important however is the relationship between BAX and BCL-2. BAX activity leads to mitochondrial changes resulting in the release of cytochrome $\mathrm{c}$ from mitochondrium to cytosol and its binding with apoptotic protease activating factor (APAF-1) and activation of procaspase-9. APAF-1, cytochrome $\mathrm{c}$ and procaspase-9 form a complex termed apoptosome which after binding with 2-CdATP leads in consequence to activation of caspase-9 cascade (intrinsic pathway) [49,50] (Figure 3). However, the role of BAX protein in PNA-induced apoptosis is still controversial. Bosanquet et al. [50] demonstrated that BAX expression correlates with sensitivity to doxorubicin (DOX), cyclophosphamide (CY) and chlorambucil ( $\mathrm{Chl}$ ), but not to 2-CdA. This finding suggests that the resistance to 2-CdA in CLL cells is due to activation of pathways other than those activated by anthracyclines and alkylating agents. On the other hand, it is also known that 2-CdA-TP induces apoptosis by direct mitochondrial pathway [20]. It can directly bind to proteins located in mitochondrial membrane resulting in the release of either cytochrome and formation of apoptosome or apoptosis inducing factor (AIF). The AIF protein leads to chromatin condensation and DNA fragmentation without the caspase-9 cascade activation [50].

Induction of apoptosis by 2-CdA via the death receptor Fas/CD95 on extrinsic pathway remains controversial [48,49]. Nomura et al. [46] have shown that apoptosis of leukemic cells in response to 2CdA could be mediated through Fas/FASL pathway. In contrast, Klopfer et al. [51] have documented that apoptosis induced by 2-CdA is independent of CD95/Fas receptor or of direct effect on APAF-1, and rather follows the mitochondrial signaling pathway of cytochrome and caspase- 9 cascade activation.

The clinical pharmacokinetics of 2-CdA have been evaluated in patients with lymphoproliferative diseases and acute leukemias. The initial evaluation of this agent was conducted using a continuous infusion for 5 to 14 days [52]. However, in subsequent studies short i.v. infusions, oral and subcoutaneus (s.c.) administrations have been utilized [53-55]. Plasma concentrations of this agent were determined either with high performance liquid chromatography or radioimmunoassay [56,57].

In the treatment of lymphoid malignancies 2-CdA is usually administered i.v. in a dose of 0.12-0.14 $\mathrm{mg} / \mathrm{kg}$ in continuous or 2-hour infusion. The mean plasma concentration is $2,0 \mathrm{mM}$, wherease the plasma drug level during the 24-hour infusion is $23 \mathrm{mM}$ [57]. Lilemark and Juliusson [56,58] showed that the $\mathrm{T}_{1 / 2} \gamma$ of plasma 2-CdA was about eight hours. The same authors have shown a $\mathrm{T}_{1 / 2} \gamma$ of 6.3 hours after a 2-hour infusion of 2-CdA which permits the drug to be administered as an intermittent infusion without loss of antitumor activity [56]. In population pharmacokinetics study performed by Lindelman et al [59] clearence of 2-CdA was $39.3 \mathrm{~L} /$ hour with a large interindividual variability. The $\mathrm{T}_{1 / 2}$ for the terminal phase was 16 hours. 
2-CdA can also be administered orally. However, oral administration of 2-CdA solution induces degradation to 2-chloroadenine, which can be overcome by doubling the dose. The bioavailability after oral administration of 2-CdA is $35-55 \%$ [60]. Maximum oral bioavailability after the dose of 0.18 $\mathrm{mg}$ /day dissolved in phosphate buffer solution is $55 \%$ [54].

The study of Juliusson et al. [61] has shown that 2-CdA can also be administered in s.c. injections. It was shown that there is $100 \%$ 2-CdA bioavailability after subcutaneous administration with a high peak concentrations of short duration with an area under the curve (AUC) very similar to those achieved with a 1-hour i.v. infusions [54]. After the subcutaneous dose of $3.4 \mathrm{mg} / \mathrm{m}^{2}$ body surface area, the median AUC in plasma following the first injections was $567.5 \mu \mathrm{mol} / \mathrm{L} / \mathrm{h}$ (range 140 to 356 $\mu \mathrm{mol} / \mathrm{L} / \mathrm{h}$ ). The median $\mathrm{T}_{1 / 2}$ of 2-CdA in plasma was 7.9 hours following s.c. injection, as compared to 9.9 hours following bolus infusions [54,61]. It should be noted that there were no local or other side effects using the s.c. route, except for the systemic effects.

\subsection{Pentostatin}

DCF (2'-deoxycoformycin) is isolated from fermentation cultures of Streptomyces antibioticus or Aspergillus nidulans. Chemically the drug is a tetrahydroimidazo\{4,5-d [1,3]diazepine ring linked to deoxyribose (Figure 1). DCF is an irreversible inhibitor of adenosine deaminase (ADA), which results in intensive conversion of adenosine (Ado) and deoxyadenosine (dAdo) into inosine nucleoside derivatives [62]. ADA is a critical enzyme in the salvage of purines, catalyzing the irreversible deamination of adenosine to inosine and deoxyadenosine to deoxyinosine [63]. ADA prevents the accumulation of deoxyadenosine-5'-triphosphate (dATP), which becomes cytotoxic at high concentrations [9]. In consequence, DCF-mediated inhibition of ADA causes accumulation of triphosphate metabolites in cytosol and inhibits DNA synthesis in dividing cells. Induction of DNA breaks and inhibition of DNA repair as well as inhibition of RNA transcription play an important role in the mechanism of DCF action [62,64]. Moreover, increased levels of Ado or dAdo derivatives in non-dividing cells can lead to unbalanced ratio between $S$-adenylmethionine and $S$-adenylhomocysteine, thus impairing the synthesis of methylated nucleosides [62,64]. Inhibition of RNA transcription, induction of DNA breaks and inhibition of DNA repair play the important role in the mechanism of DCF action.

Studies on pharmacokinetics of DCF revealed that plasma concentration measured at one hour after i.v. administration was proportional to the dose of pentostatin in the range 7.5 to $30 \mathrm{mg} / \mathrm{m}^{2}$ [64]. Plasma concentration of DCF was best fitted to a two-compartment open model [65]. The mean $\mathrm{T}_{1 / 2} \alpha$ ranged from 8.72 to 60 minutes, followed by the terminal phase of 4.93 to 10 hours [66,67]. The mean apparent $\mathrm{Vdr}$ was $23.1 \pm 6.16 \mathrm{~L} / \mathrm{m}^{2}$, and the mean Vdss was $20.1 \pm 5.01 \mathrm{~L} / \mathrm{m}^{2}$. The similarity of these values suggests that DCF does not achieve extensive tissue binding [65]. The drug crosses the bloodbrain barrier with concentration in the CSF of 10 to $20 \%$ of that in plasma [68]. Pentostatin is predominantly excreted unchanged by kidneys and approximately $95.9 \%$ of the administered dose is present in the urine. Total body clearance is $52.4 \pm 16 \mathrm{~mL} / \mathrm{min} / \mathrm{m}^{2}$ and correlates with creatinine clearance [65]. In the treatment of lymphoid malignancies, DCF is generally administered at a dose of $4 \mathrm{mg} / \mathrm{m}^{2}$ as an i.v. bolus or short (20 to $30 \mathrm{~min}$ ) infusion [69]. 


\subsection{Clofarabine}

Clofarabine [2-chloro-9-(2'-deoxy-2'-fluoro- $\beta$-D-arabinofuranosyl) adenine] belongs to the second generation of PNAs. It has been synthesized to combine the most favorable pharmacokinetic properties of fludarabine and cladribine [70-72]. The structure of CAFdA, similarly to 2-CdA, consists of deoxyadenosine with substitution of hydrogen by chlorine at the 2-position of the adenine ring causes electronic changes that make the amino group resistant to deamination by ADA (Figure 2) [32]. Substitution of a fluorine atom at the arabinosyl configuration at the 2'-position of the carbohydrate decreased the susceptibility of CAFdA to phosphorolytic cleavage by PNP. Additionally, it makes CAFdA more acid stable and leads to an increase of its oral bioavailability [73].

Clofarabine is a slightly lipophilic drug entering into the cells also via NT systems, and at higher concentration and longer exposure time, by passive diffusion across lipid membranes [74]. The drug is transported via hENT1, hENT2, hCNT2 and hCNT3 (24). Like other PNA, CAFdA, after the uptake into the cells, is converted by $\mathrm{dCK}$ to the 5'-monophosphate metabolite, and then by mono- and diphosphokinases to the active 5'-triphosphate form (CAFdA-TP). dCK phosphorylates CAFdA with a $50 \%$ lower Michaelis-Menten constant $\left(\mathrm{K}_{\mathrm{M}}\right)$ but a 4-fold higher maximum velocity $\left(\mathrm{V}_{\max }\right)$ than the physiological substrate deoxycytidine (dCy) [75,76]. Additionally, clofarabine was reported to be more efficient substrate for purified recombinant dCK than FA and 2-CdA [75,77]. Since CAFdA inhibits $\mathrm{RR}$, it has been suggested that this drug may increase cellular dCK activity and enhance its own activation [71]. dCK is known to be rate-limiting enzyme for many of adenosine analogues, but is not rate limiting with clofarabine and clofarabine 5'-monophosphate that serves as a reservoir for the formation of 5'-triphosphate metabolites [78].

Clofarabine acts via three mechanisms of action: incorporation into DNA, inhibition of RR, and induction of apoptosis. The clofarabine triphosphate form (CAFdA-TP) is required for its cytotoxicity. CAFdA, in contrast to other anticancer drugs but similarly to the whole PNA class, is active both in mitotic and quiescent cell cycle phase [71]. The cytotoxicity of CAFdA-TP in the dividing cells is mainly due to the inhibition of either DNA polymerases or RR, leading to disequilibrium in deoxynucleotide triphosphates pool and via endonuclease activation results in DNA strand breaks [79]. The incorporation of the monophosphate of CAFdA into DNA by DNA polymerase $\alpha$ results in chain termination and strand breakage. The inhibition of RR in consequence reduces the amount of intracellular dNTP available for DNA synthesis, mainly deoxycytidine triphosphate (dCTP) and dATP but not deoxytymidine triphosphate (TTP) [79]. The depletion of the dCTP pool is sufficient to limit DNA synthesis, and reduction in dATP concentration allows CAFdA-TP to compete with dATP for incorporation into DNA [71,79]. In comparison with FA and 2-CdA, CAFdA inhibits more completely both RR and DNA polymerases [75,77]

Clofarabine can also induce apoptosis, and both P53-dependent and P53-independent mechanisms of cytotoxicity are suggested [6]. Additionally, CAFdA-TP similarly to 2-CdA can induce apoptosis by binding directly to proteins located in mitochondrial membrane. Thus, the direct mitochondrial effects of CAFdA and 2-CdA may explain why these drugs are toxic to CLL cells at concentrations 5-10-fold lower than FA (Figure 4) [72,80]. 
Figure 4. Mechanism of clofarabine, nelarabine and forodesine action.

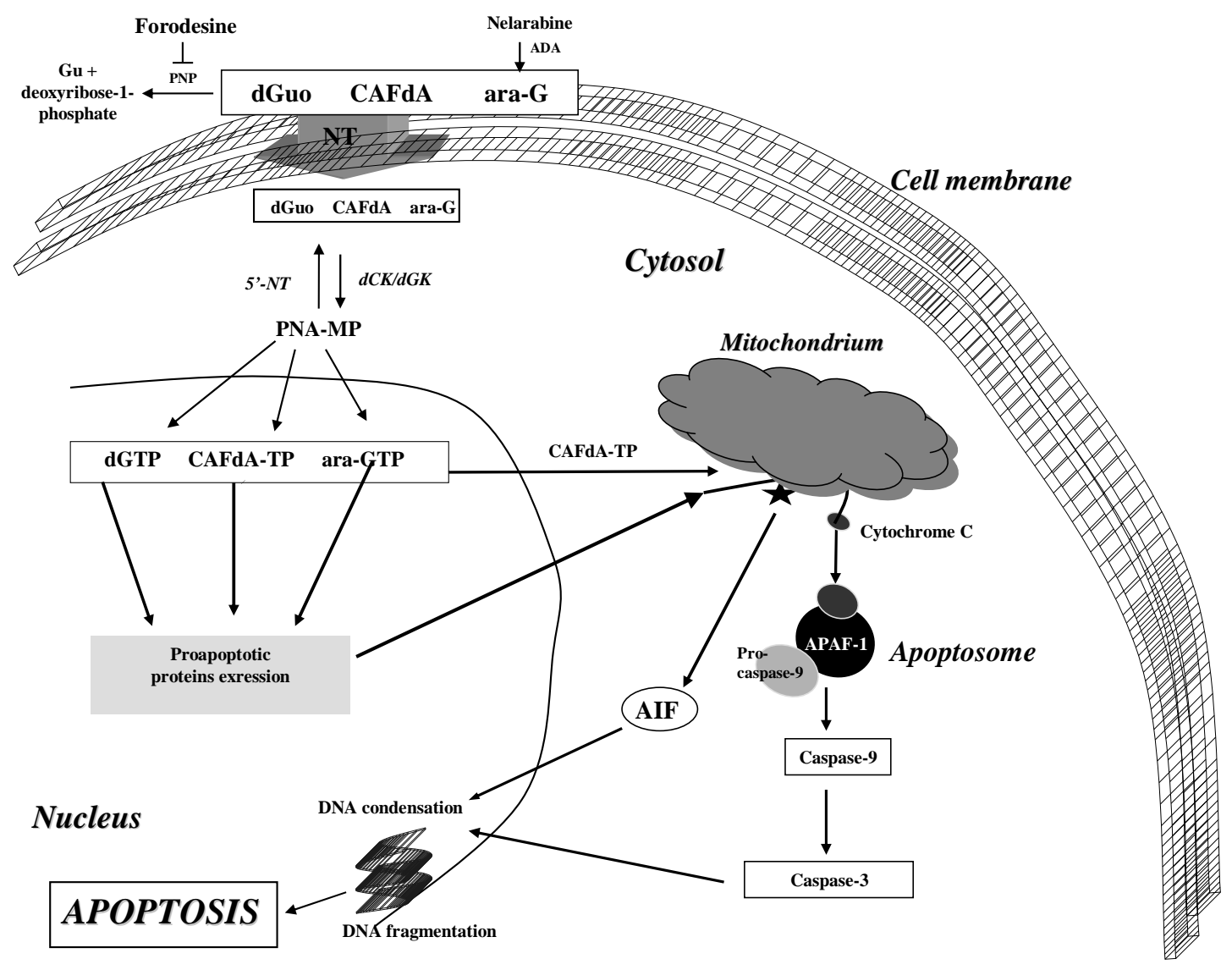

CAFdA-clofarabine; PNA-MP-purine nucleoside analogue's monophosphate; CAFdA-TPclofarabine triphosphate; Gu-guanine; dGuo-deoxyguanosine; ara-G-arabinosylguanine; ara-GTP-arabinosyl triphosphate; dGTP-deoxyguanosine triphosphate; ADA-adenine deaminase; NT-nucleoside transporter; 5'-NT-5'-nucleotidase; dCK-deoxycytidine kinase; AIF-apoptosis-inducing factor; APAF-1- apoptotic protease activating factor

The pharmacokinetics of CAFdA were evaluated both in adult and pediatric patients in the phase I studies $[78,81,82]$. During the initial phase I clinical studies conducted in patients with hematological malignancies and refractory solid tumours the maximum tolerated doses (MTD) and the dose-limiting toxicities (DLT) were assessed [78,82,83]. CAFdA was given as a 1-hour infusion daily for five days, every 3 to 6 weeks. The recommended dose for phase II studies was $40 \mathrm{mg} / \mathrm{m}^{2}$ i.v. for five days in patients with acute leukemias, MDS and CML-BP [78,81]. In patients with chronic lymphoproliferative disorders (LPDs) and solid tumors, the DLT was myelosuppression at the dose of $15 \mathrm{mg} / \mathrm{m}^{2}$, therefore in these patients CAFdA at the doses of $2 \mathrm{mg} / \mathrm{m}^{2}$ or $4 \mathrm{mg} / \mathrm{m}^{2}$ i.v. daily for five days were recommended for phase II clinical trials [82].

After administration of CAFdA at a dose of $40 \mathrm{mg} / \mathrm{m}^{2}$ as a 1-hour i.v. infusion, the median plasma level of CAFdA was $1.0 \mu \mathrm{M}$ (range $0.26-1.94 \mu \mathrm{M}$ ) [81]. The peak level of CAFdA in plasma occurred at the end of the infusion and a linear increase in plasma CAFdA concentration with increasing doses was observed [78]. Clofarabine was only $47 \%$ bound to plasma proteins, predominantly to albumin and showed extensive tissue distribution, having a $\mathrm{V}_{\mathrm{dss}}$ of $179 \mathrm{~L}$ for a $40-\mathrm{kg}$ patient (about $4.5 \mathrm{~L} / \mathrm{kg}$ ) 
$[71,78]$. CAFdA appeared to be eliminated in a biphasic manner with faster kinetics during the first 6 hours followed by slower kinetics up to 24 hours $[71,82,83]$. The pathway of elimination is primarily via renal excretion, and the renal clearance was $10.8 \mathrm{~L} / \mathrm{h} / \mathrm{m}^{2}$ with $57 \%$ of the dose excreted unchanged in the urine $[71,78]$. The total systemic clearance for clofarabine was $28.8 \mathrm{~L} / \mathrm{h} / \mathrm{m}^{2}$.

Similar to plasma CAFdA levels, the concentration of intracellular CAFdA-TP measured in circulating leukemic blasts varied among patients and the median value was $15 \mu \mathrm{M}$ with a range of less than $1 \mu \mathrm{M}$ to $44 \mu \mathrm{M}$ [81]. No differences were observed between myeloid and lymphoid leukemic blasts regarding the retention of intracellular CAFdA-TP [81].

\subsection{Nalarabine}

Nelarabine [6-methoxy-9-( $\beta$-D-arabinofuranosyl) guanine] is a prodrug of 9- $\beta$-D-arabinofuranosylguanine (ara-G). It belongs to the guanosine analogues in which at the 6-position of guanine ring the hydrogen of a hydroxide group is substituted by a methoxy group (Figure 2) [84].

In blood nelarabine is rapidly demethoxylated to ara-G by ADA and afterwards it permeates the cell via $p$-nitrobenzylthioinosine-sensitive and insensitive hENTs [85]. In contrast to other PNA, the active metabolite of nelarabine is not its triphosphate form but instead ara-G is phosphorylated by either dCK to cytosolic ara-GTP or dGK to mitochondral ara-GTP [86]. On the other hand, deactivation of nucleosides occurs partly through either deamination by ADA or dephosphorylation by 5'-NT and partly by cleavage of glucosidic bond by the active bacterial enzyme PNP [86].

The first limiting step in the formation of ara-GTP is initial phosphorylation of ara-G to monophosphate (ara-GMP) and afterwards via diphosphate (ara-GDP) to its triphosphate form (araGTP), which upon incorporation into DNA, results in DNA breaks and leads to apoptosis [21]. The ara-G competes with native deoxynucleosides as a substrate for incorporation into DNA by DNA polymerases. It results in inhibition of DNA synthesis and initiation of apoptosis. On the other hand, ara-G is also able to induce apoptosis in T cells by involvement of Fas/FasL system resulting in release of soluble FasL (sFasL) and triggering death receptor mediating cell death in the bystander cells. In contrast, myeloid and B-cells accumulate lower levels of ara-GTP and arrest in S-phase, blocking any apoptotic signaling [87]. Nelarabine has consistently been reported to be more cytotoxic in T-lineage than in B-lineage leukemias [21,88,89]. Beeslay et al. [90] have confirmed above results and shown that nelarabine is particularly effective in T-cell ALL, however a subset of patients with B-lineage ALL might also be sensitive.

Pharmacokinetics of nelaribine was evaluated in patients with hematologic malignancies. Nelarabine levels reached a median peak value of $18 \mu \mathrm{mol} / \mathrm{L}$ at the end of the infusion. After the end of the nelarabine infusion, the concentration of this agent declined with time in a monoexponential fashion with a mean $\mathrm{T}_{1 / 2}$ of 14.1 minutes in pediatric and 16.5 minutes in adult patients [91]. The maximum plasma concentration $\left(\mathrm{C}_{\max }\right)$ of ara-G occurred within 15 minutes after the end of the 1-hour infusion of nelarabine. The $C_{\max }$ of ara-G ranged from $11.6 \mu \mathrm{mol} / \mathrm{L}$ to $308.7 \mu \mathrm{mol} / \mathrm{L}$ at nelarabine doses of 5 to $75 \mathrm{mg} / \mathrm{kg}$ and was linearly related to these doses. In contrast to nelarabine, ara-G was eliminated from plasma slowly with a median $\mathrm{T}_{1 / 2}$ of 4.2 hours (range 1.8 to 5.6 hours) [91]. The pharmacokinetic parameter estimates of ara-G have showed that blasts from patients with T-ALL or Tlymphoid CML-BP accumulated relatively greater levels of ara-GTP compared to other lineages [92]. 
It was observed that clearance (CL) of ara-G was higher in pediatric patients as compared to adults, although it may be associated with age-related differences in renal function.

\subsection{Forodesine}

Forodesine belongs to 9-deazanucleoside analogues which are termed immucillins. The structure of these agents based on "nitrogen in the ring" of D-ribofuranose and C-glycosidic bond analogues of natural nucleosides $[93,94]$. These agents are C-nucleosides containing nitrogen atom in the ring of Dribofuranose. Forodesine, chemically described as [7-(3,4-dihydroxy-5-hydroxymethylpyrrolidyn-2yl)-3,5-dihydropyrrolo-[3,2-d] pyrimidin-4-one], is one of the most potent members of this group (Figure 2) [93-95]. In contrast to other PNAs, for which the active forms are nucleoside triphosphates, in case of forodesine, the nucleoside is the active form. The drug does not act via incorporation into DNA and inhibition of DNA synthesis, but displays a highly selective PNP inhibitory action [22].

In the mechanism of forodesine action, apart from PNP two other enzymes, dCK and dGK, are involved. Normally the affinity of dGuo is higher for PNP than for dCK. Nevertheless, in the absence of PNP plasma dGuo reaches high level and is not cleaved to Guo, but instead of it is intracellularly converted mainly by dCK or dGK to dGMP, and then by mono- and diphosphokinases to the active dGTP $[15,96]$.

However, similarly to other purine nucleoside, the first step of the cellular activity of dGuo is their uptake into the cells which occurs via one or more of NT. In order to be biologically active, dGuo needs to be phosphorylated intracellularly, and its cytotoxicity depends on accumulation of dGMP in the cells. Accumulation of dGTP as a result of forodesine action leads to RR inhibition, imbalance of dNTP pool, inhibition of either DNA synthesis or DNA repair, which results in accumulation of DNA breaks [97,98]. DNA damage due to inhibition of DNA repair and accumulation of DNA breaks leads to the P53 expression which plays a key role in the control of apoptosis and cell cycle $[6,15]$. It has been recently demonstrated that post-translational modification of P53 is required for its stability and activation following cell stress and is a determinant of P53-mediated apoptosis [99]. Balakrishnan et al. [22] have recently shown that forodesine treatment also results in post-translational modification of P53, its stability, and P53 dependent P21 activation.

On the other hand, similarly to other cells which were treated with PNAs, in cells showing an accumulation of dGTP as a result of forodesine action, apart from intrinsic cell death pathways connected with DNA damage and P53 protein expression, a direct mechanism connected with MPT pore and resulting in the release of proapoptotic proteins has been also described (Figure 4). Additionally, an extrinsic pathway via death receptor Fas/CD95 can be also important [5,22].

The bioavailability after oral administration of forodesine in mice was $63 \%$. At a single dose of 10 $\mathrm{mg} / \mathrm{kg}$ the drug increased dGuo accumulation to approximately $5 \mu \mathrm{M}$ [17]. After increasing the oral administration of forodesine up to $10 \mathrm{mg} / \mathrm{kg}$ no further increase in dGuo was observed. In vivo studies in primates revealed that oral and i.v. administration of forodesine induced a rapid elevation of plasma 2'-dGuo and that oral dosing at 8.8 and $17.6 \mathrm{mg} / \mathrm{kg}$ were at least equivalent to $4.4 \mathrm{mg} / \mathrm{kg}$ i.v. twice daily in effecting 2'-dGuo accumulation. Increasing the i.v. dose of the drug did not increase dGuo accumulation; however plasma dGuo concentration remained elevated longer. In contrast, the increase of oral doses resulted in elevated plasma dGuo accumulation [100]. In human blood dGuo is degraded 
rapidly with a $T_{1 / 2}$ of 12 sek. and for achieving dGuo concentration needed to a significant reduction of T-cell function the continuous inhibition of PNP greater than $95 \%$ is required $[96,98]$.

\section{Clinical activity}

The activity of PNAs in the treatment of lymphoid malignancies is documented in several clinical trials. 2-CdA and DCF are useful agents in the treatment of HCL. These drugs are also active in the treatment of low -grade B- and T-cell NHL. Moreover, FA, 2-CdA and DCF administered in CLL patients as monotherapy as well as a combined treatment either with other cytotoxic agents or monoclonal antibodies demonstrate high response rates. Two of new PNAs - forodesine and nelarabine - are also active in lymphoid malignancies, especially in acute T-cell lymphoblastic leukemia.

\subsection{Hairy cell leukemia}

2-CdA and DCF are the drugs of choice in the treatment of HCL. In contrast, FA is less active in the treatment of this disease and only minor clinical experience has been reported so far [1,2]. Piro et al. [101] were the first to describe sustained complete response (CR) in HCL patients who had undergone splenectomy and received a single continuous i.v. infusion of 2-CdA for seven days. Further multiple studies on larger groups of patients demonstrated that 2-CdA induces durable and unmaintained $\mathrm{CR}$ in about $80 \%$ of patients after a single course of therapy [105-120]. 2-CdA is administered either as a continuous i.v. infusion at a dose of $0.09 \mathrm{mg} / \mathrm{kg}$ over a $5-7$ days period or as a 2-hour i.v. infusion at a dose of $0.12 \mathrm{mg} / \mathrm{kg}$ for 5-7 days [55,102,103]. However, similar results were achieved when the drug was given in s.c. injection [104]. Preliminary observations indicated that a CR following 2-CdA administration was durable even without maintenance therapy, so this drug was considered as potentially curative against HCL [105-109]. However, a long-term clinical follow-up of patients who had entered CR also after a single course of 2-CdA revealed that about $20 \%$ of them relapsed [109-111].

2-CdA is highly effective in relapsed disease. Goodman et al. [109] has reported the results of retreatment with this agent. The overall response rate of relapsed patients who were retreated with 2CdA was $90 \%$ with $75 \%$ achieving a CR and 10 (17\%) a partial response (PR). The median second response duration for all responders was 35 months while the median time to first relapse was 42 months. The second relapse was observed in 20 patients and 10 of them received second re-treatment with 2-CdA. Overall response rate was $80 \%$ including $60 \%$ of CRs. The median of the third response duration was 20 months.

2-CdA is also an effective drug when administered at a dose of $0.15 \mathrm{mg} / \mathrm{kg}$ in a 2-hour infusion once a week over 6 courses. In the study by Lauria et al. [112] 22/30 (73\%) patients with HCL achieved a CR and 8 (27\%) patients achieved a PR when 2-CdA was given in this mode. This type of drug administration may be less toxic and reduces the risk of infection complications in comparison with standard 2-CdA daily regimens. In our randomized study we compared weekly administration of 2-CdA $(0.12 \mathrm{mg} / \mathrm{kg}$ in a 2-h i.v. infusion once a week for 6 weeks) with daily administration $(0.12$ $\mathrm{mg} / \mathrm{kg}$ in a 2-h i.v. infusion for 5 consecutive days) [113]. The updated results of this study indicate 
that both $\mathrm{CR}$ and overall response (OR) rates were similar in compared groups. There was no statistically significant difference in toxicity between groups, except for thrombocytopenia. It seems, however, that daily administration of 2-CdA may more frequently induce thrombocytopenia and neutropenia and lead to more frequent infections.

In the study of Juliusson et al. [114,115], 73 patients were given 2-CdA as a subcutaneous injection once daily for seven days. Fifty-nine patients $(81 \%)$ achieved a durable CR after one $(\mathrm{n}=55)$ or two courses and 10 had a PR. With a median follow-up duration of 20 months no patients had a clinical relapse. Similar study was performed by von Rohr et al. [104]. In this multicenter phase II trial, 62 patients received a first cycle with 2-CdA at a dose of $0.14 \mathrm{mg} / \mathrm{kg} /$ day by s.c. bolus injection for five consecutive days. Complete and partial response were seen in $47(76 \%)$ and $13(21 \%)$ patients, respectively. At a median follow-up of 3.8 years, progression after PR was seen in seven patients and relapse after $\mathrm{CR}$ was seen in eight patients. The above two trials may indicate that 2-CdA given by s.c. bolus injections is very effective in HCL and more convenient for patients than continuous i.v. infusion.

In 1984, Spiers et al. [116] first demonstrated that DCF is a highly active agent in HCL. Subsequently the Eastern Cooperative Oncology Group conducted a multicenter study of DCF in patients with this disease [117]. The initial dose was $5 \mathrm{mg} / \mathrm{m}^{2}$ administered on three consecutive days every four weeks, but this was later modified to $5 \mathrm{mg} / \mathrm{m}^{2}$ given on two consecutive days every two weeks. Among the 27 eligible patients, the response rate was 96\% with 16 (59\%) patients who entering a CR and 10 (37\%) patients achieving a PR. These observations were later confirmed by several centers [118-129]. In these studies DCF was usually used at a dose of $2-4 \mathrm{mg} / \mathrm{m}^{2}$ i.v. every second week although other schemes were also applied. Ranges of CR rate varied from 40 to $90 \%$ regardless of prior treatment with IFN- $\alpha$ or splenectomy [120-127]. The drug is well tolerated in HCL, especially when neutropenia is not severe or there is no history of life-threatening infections. Myelosuppression is the main toxicity and may require delays in planned chemotherapy schedule [119].

A randomized study comparing DCF with IFN- $\alpha$ has demonstrated that DCF produced a higher CR and PR rate with more durable responses in HCL [129]. In that study patients were randomized to receive either IFN- $\alpha\left(3 \times 10^{6} \mathrm{U}\right.$ s.c. three times per week) or DCF $\left(4 \mathrm{mg} / \mathrm{m}^{2}\right.$ i.v. every two weeks). Patients who did not respond to initial treatment were crossed over. Among IFN- $\alpha$ patients, 17 of 159 (11\%) achieved a confirmed CR or PR. Among DCF patients, 117 of 154 (76\%) achieved a confirmed CR and 121 of 154 (78\%) had a unconfirmed CR (CRu) or PR. Response rates were significantly higher $(\mathrm{p}<0.0001)$ and relapse-free survival was significantly longer with DCF than IFN- $\alpha$ ( $\mathrm{p}<$ 0.0001). Subsequently, long-term data on duration of overall survival and relapse-free survival data from this study were reported. Estimated a 5- and 10-year survival rates for all patients were $90 \%$ and $81 \%$, respectively. Moreover, only two of 40 deaths were attributed to HCL. Other long-term observations also confirmed that DCF induces a high rate of long-lasting CR both in patients previously untreated and in patients pretreated with IFN- $\alpha$ or splenectomy [120-127].

2-CdA and DCF seem to induce similar high response rates but only a large randomized trial with the two agents will be able to evaluate the $\mathrm{CR}$ rates, duration of response, recurrence rates and adverse events, which have appeared to be comparable so far. Recently, Else et al. [129] have reviewed a series of 219 patients with HCL, with a median follow-up from the diagnosis of 12.5 years (range 1.0 $34.6 \mathrm{yrs})$ treated either with DCF $(n=185)$ or 2-CdA $(n=34)$, to compare the effectiveness of these 
agents. Overall response to DCF was $96 \%$ with a CR in $81 \%$ and median disease free survival (DFS) of 15 years. Response to first line 2-CdA was $100 \%$ with a CR in $82 \%$ and DFS of $11+$ years. Diseasefree survival (DFS) showed no plateau in both groups. The relapse rates at five years and ten years were $24 \%$ and $42 \%$, respectively, with DCF and $33 \%$ and $48 \%$ with 2-CdA. Survival at ten years was $96 \%$ in DCF group and $100 \%$ in the 2 -CdA group. This study has confirmed previous observations that DCF and 2-CdA are equivalent in the treatment of HCL. The effectiveness of FA in the treatment of HCL is not as good as 2-CdA or DCF and only minor clinical experience has been reported so far [130].

\subsection{Chronic Lymphocytic Leukemia}

Fludarabine and 2-CdA are highly active in CLL, both previously treated and untreated [131-140]. The results of the studies presented so far have shown that both drugs give a similar CR rate and overall response (OR) rate, but the influence of these agents on survival times is still uncertain [136, 138]. The CR rate induced with PNA is significantly higher than in patients treated with conventional chemotherapy. In refractory or relapsed patients FA has an OR rate of $12-73 \%$, including CR in the range of 0-25\% [136-138].

Cladribine has also been found to be quite effective in the treatment of patients with CLL, even when they are resistant to other therapies. The activity of 2-CdA in patients with CLL resistant to conventional treatment was first reported in 1988 by Piro et al. [140]. The OR was obtained in 10 of 18 patients. In our study among 184 pretreated patients, a CR was obtained in $23(12.5 \%)$ and a PR in 66 (35.9\%), giving an OR rate of 48.4\% (44). Pentostatin has been also less extensively tested in CLL than FA. In several series this agent demonstrated about $25 \%$ response rate [138].

The results of randomized phase III trials indicate that PNA are more active than alkylating agents in previously untreated CLL patients [131-135]. Rai et al. [136] have published the results of a longterm randomized, multicenter trial comparing FA with Chl in advanced CLL. They randomized 509 patients with Rai stage I and II CLL with disease-related symptoms and all patients in the high-risk category (Rai stage III or IV). Patients were randomly assigned to one of the three arms: FA, chlorambucil or FA plus chlorambucil. Assignment of patients to the FA plus Chl group was stopped after the interim analysis because of the excessive toxicity and a response rate not better than after FA alone. Among the other two groups the OR rate was significantly higher for FA (63\%) than for Chl $(37 \%)(p<0.001)$. The CR was also higher in FA group $(20 \%)$ than in the Chl group $(4 \%)(p<0.001)$. The median duration of response and median PFS of the patients treated with FA was 25 months and 20 months, respectively. In contrast both values were 14 months in the Chl group. However, there was no significant difference in the median overall survival in the both groups (66 and 56 months in FA and Chl group, respectively) ( $p=0.21)$.

High CR and OR rates in CLL patients treated with 2-CdA as first-line therapy were also obtained in a prospective, randomized, multicenter trial [132,133]. In this study we compared the efficacy and toxicity of 2-CdA with prednisone and $\mathrm{Chl}$ plus prednisone in previously untreated patients with progressive and advanced CLL. Of 229 evaluated patients, 126 received 2-CdA with prednisone and 103 received $\mathrm{Chl}$ with prednisone. The data obtained from this trial indicate that the OR rate after 2$\mathrm{CdA}$ and prednisone therapy was significantly higher than that after $\mathrm{Chl}$ and prednisone treatment 
(97\% and 57\%, respectively, $\mathrm{p}<0.001)$. Moreover, the clinical OR rate after 2-CdA was also significantly higher $(47 \%)$ than that after Chl treatment $(12 \%)(\mathrm{p}<0.001)$. Likewise, progression-free survival (PFS) was significantly longer in the 2-CdA treated group $(\mathrm{p}=0.01)$. However, there was no difference in overall survival duration between the two groups and no difference in event-free survival.

The treatment of outpatients is more convenient when oral formulation of chemotherapeutic agents is available. Recently, an oral formulation of FA was developed with equivalent efficacy and tolerability to the i.v. formulation [142]. The pharmacokinetic studies demonstrated that FA at the oral dose of $40 \mathrm{mg} / \mathrm{m}^{2}$ used a once-daily provides a systemic exposure similar to that of $\mathrm{FA}$ administered i.v. at the dose of $25 \mathrm{mg} / \mathrm{m}^{2} /$ day

Among cytotoxic agents alkylating drugs and anthracyclines were the most frequently combined with PNA. O'Brian et al. [143] have treated a total of 128 CLL patients with FA at a dose of $30 \mathrm{mg} / \mathrm{m}^{2}$ for 3 days and CY at either 500,350 or $300 \mathrm{mg} / \mathrm{m}^{2} /$ day (FC program for three days). Some of these patients were previously untreated; others had been treated with alkylating agents and/or FA. More than $80 \%$ of patients not refractory to FA alone responded to combined treatment and a $38 \%$ response rate was observed in patients who were refractory to FA given earlier as monotherapy. In previously untreated patients, a CR rate (35\%) was similar to that observed earier in CLL patients treated with FA alone. However, in previously untreated patients treated with FA and CY who obtained a CR, minimal residual disease (MRD) was seen in only $8 \%$ and the median time to progression had not been reached after the median observation of 41 months. Higher efficacy of the FC protocol compared with FA alone has been confirmed in three phase III trials of treatment naive patients with advanced/progressive CLL.[144-147]. The German CLL Study Group have compared FC regimen with the standard regimen of FA monotherapy in first line treatment of younger than 66 years patients with advanced CLL [145]. In total, 375 patients were randomized to the arm treated with FA (25 $\mathrm{mg} / \mathrm{m}^{2} /$ day for five days) or to the arm treated with FA $\left(30 \mathrm{mg} / \mathrm{m}^{2} /\right.$ day $)$ plus CY $\left(250 \mathrm{mg} / \mathrm{m}^{2} /\right.$ day $)$ on days one to three every 28 days. Of 207 patients evaluated for response, OR was higher in the FC regimen $(94 \%)$ than in the FA group (83\%; $p<0.01$ ), and CR was $24 \%$ versus $7 \%$, respectively $(p=$ 0.01). The median PFS was 20 months in patients treated with FA alone and 48 months in patients treated with the FC regimen $(\mathrm{p}=0.001)$. Thus far, no difference in median overall survival (OS) has been observed. Similar results were obtained in the US Intergroup Trial E2997 [145]. Symptomatic previously untreated patients with CLL were treated with FA alone or FA plus CY. A total of 278 patients were randomly assigned in this intergroup study. FC combination chemotherapy results in a significantly higher $\mathrm{CR}$ rate $(23.4 \%)$ and an OR rate $(24.3 \%)$ compared with $\mathrm{FA}$ alone (46\% and $59.5 \%)(p<0.01$ and $p=0.013)$. FC treatment also resulted in longer PFS than those treated with FA alone (31.6 vs 19.2 months, $\mathrm{p}<0.0001$ ). However, FC regimen caused additional hematologic toxicity including more severe thrombocytopenia $(p=0.046)$ but did not increase the number of severe infections. In the UK LRF CLL4 trial, 777 previously untreated patients with CLL were randomly assigned to Chl, FA or to FC [147]. OR and CR rates were better with FC (94\% and 38\%, respectively) than with FA alone ( $80 \%$ and $15 \%$, respectively), wchich were in turn better than with $\mathrm{Chl}(\mathrm{OR}-72 \%$, CR $-7 \%)$. The PFS at five years was significantly better with FA + CY (36\%) than with FA (10\%) or $\mathrm{Chl}(10 \% ; \mathrm{p}<0.00005)$. However, there was no significant difference in OS between patients given FC, FA alone or Chl. Moreover, patients had more neutropenia and days in hospital with FC or FA, than with Chll. Interestingly, there were less autoimmune hemolytic anemias with FC (5\%) than with 
FA $(11 \%)$ or $\mathrm{Chl}(12 \%)$. The results of these randomized trials indicate, that FC should now become the standard treatment for CLL and the basis for new protocols that incorporate monoclonal antibodies [147].

Cladribine combined with CY has been also investigated in phase II studies both in previously treated and untreated patients [148,149]. Montillo et al. [148] treated 29 patients with refractory or recurrent CLL or prolymphocytic leukemia (PLL) with 2-CdA $\left(4 \mathrm{mg} / \mathrm{m}^{2} /\right.$ day) for three days every four weeks. Eleven patients (38\%) had a response with the median response duration being 12 months. We determined the effectiveness and toxicity of 2-CdA in combination with $\mathrm{CY}$ (CC regimen) in patients with previously untreated CLL [150]. In the analyzed group of 82 patients the OR rate was $87.8 \%$, which included a CR rate of $29.3 \%$. Minimal residual disease was detected in only six of $24(25 \%)$ patients with CR. Grade 3-4 thrombocytopenia was seen in four patients (5\%) and neutropenia in ten patients (12\%). Severe infections were noted in 21 (25\%) patients. Recently, we performed an interim analysis of a randomized study that compared the activity and toxicity of 2-CdA and CY (CC programe) versus FA and CY (FC program) in previously untreated progressive or symptomatic CLL [150]. The preliminary results of this study indicate that $\mathrm{CC}$ and FC programs used as a first-line therapy give similar CR $(46.7 \%$, vs $48.7 \%$; $p=0.43)$ and OR $(88.6 \%$ vs $85.0 ; p=0.31)$ rates and both regimens have comparable toxicity.

Pentostatin combined with CY may be also more effective than when given as monotherapy. In one study refractory or relapsed CLL patients were treated with DCF ( $\left.4 \mathrm{mg} / \mathrm{m}^{2}\right)$ combined with CY (600 $\mathrm{mg} / \mathrm{m}^{2}$ or $300 \mathrm{mg} / \mathrm{m}^{2}$ ). Both drugs were administered on day one of each cycle and cycles were repeated every three weeks for six courses [151]. There were 17 responses (74\%), including four CRs. It is worth noting that the response rate was $77 \%$ in FA refractory patients.

Recent clinical observations indicate that combinations of PNA with mitoxatrone (MIT), or MIT and CY, are also highly active regimens [152-156]. Tsimberidou et al. [152] have shown that addition of MIT to FA does not have a significant advantage over FA alone in previously treated and untreated patients with CLL. Bosch et al. [153] evaluated FA combined with CY and MIT (FCM) in 60 patients with resistant or relapsed CLL. Overall, 30 (50\%) patients achieved a CR, including 10 (17\%) cases of negative MRD. The PR was achieved in 10 (17\%) patients. The median duration of response was 19 months. The FCM regimen was well tolerated and could be administered on an out-patient basis. The results obtained with the FCM regimen appear to be better than those reported with FA alone.

In our study we determined the efficacy and toxicity of 2-CdA, MIT and CY combination (CMC protocol) in treated and untreated patients with CLL [154-156]. The OR rate was 37\% in previously treated patients and $69 \%$ in untreated patients and a CR rate was $5 \%$ and $29 \%$, respectively.

Recently, we performed a randomized multicenter study to compare the CMC with CC and 2-CdA alone in previously untreated CLL patients [156]. Compared with 2-CdA alone CMC induced higher CR rate $(36 \%$ vs $21 \% ; \mathrm{p}=0.004)$, and a trend for a higher $\mathrm{CR}$ rate with $\mathrm{CC}$ was observed $(29 \%$ vs $21 \% \mathrm{p}=0.08$ ). In addition, the percentage of patients who were in CR and were MRD negative was higher in CMC compared with 2-CdA (23\% vs $14 \%, p=0.042)$. However, there were no differences in OR, PFS and OS survival among treatment groups.

Monoclonal antibodies and chemotherapy have synergistic activity in patients with CLL $[157,158]$. Several recent reports suggest that in patients with CLL, rituximab combined with PNA can increase the OR and CR and prolonge PFS as compared with PNA or rituximab alone with acceptable toxicity 
[158-164]. The addition of rituximab to a variety of chemotherapy regimens for the treatment of patients with CLL has yielded promising results in phase II and III trials.

The combination of rituximab with FC (R-FC regimen) demonstrated particularly high rates of OR, CR, PFS, and overall survival in previously untreated and relapsed/refractory CLL [161,162]. In order to validate this concept the German CLL study group (GCLLSG) initiated a multicentre, multinational phase III trial, CLL8, to evaluate the efficacy and tolerability of R-FC versus FC for the first-line treatment of patients with advanced CLL [161]. 817 patients were randomly assigned to receive 6 courses of either FC of R-FC. At the time of analysis (June 2008) the median observation time was 25.5 months (mo). The overall response rate was significantly higher in the R-FC arm $(95 \% ; 370 / 390)$ compared to FC $(88 \% ; 328 / 371(\mathrm{p}=0.001)$. The complete response rate of the R-FC arm was $52 \%$ as compared to $27.0 \%$ in the FC arm ( $\mathrm{p}<0.0001$ ). The PFS was $76.6 \%$ at two years in the R-FC arm and $62.3 \%$ in the FC arm $(\mathrm{p}<0.0001)$. There was a trend for an increased OS rate in the R-FC arm $(91 \%$ vs $88 \%$ at two years $\mathrm{p}=0.18)$.

In REACH trial 552 relapsed or refractory patients from 17 countries were randomized (1:1) to receive either R-FC or FC [162]. A median of one prior treatment had been administered, consisting of single-agent alkylator therapy (66\%), purine-analogs $(16 \%)$, or combination treatments (CHOP, COP, F-containing, 18\%). Patients with prior FC combination treatment or prior rituximab were not eligible. Median observation time was 25 months. The primary endpoint PFS was significantly prolonged by median 10 months in the R-FC arm (30.6 months) compared to FC (20.6months, $\mathrm{p}=0.0002$ ). Secondary endpoints showed similar results. The OR rate was higher for R-FC vs. FC (70\% vs. 58\%, p $=0.0034)$, due to superior $\mathrm{CR}$ rates $(24 \%$ vs. $13 \%, \mathrm{p}=0.0007)$. Grade $3 / 4$ adverse events were higher in the R-FC arm (80\%) vs. FC (74\%), but serious adverse events were similar (50\% vs. 48\%, respectively). Grade 3/4 neutropenia and febrile neutropenia were only marginally increased for R-FC (42\% and 15\%) vs. FC (40\% and $12 \%$, respectively). The same correlation was seen for thrombocytopenia (R-FC 11\% vs. FC 9\%). Grade 3/4 infections (R-FC 18\%, FC 19\%) were similar, and there was no difference in bacterial, viral, or fungal infections between the two arms. Grade 3/4 anemia was slightly increased in the FC arm (R-FC 2\%, FC 5\%).

\subsection{Prolymphocytic leukemia}

Prolymphocytic leukemia (PLL) is characterized by splenomegaly and high circulating lymphoid cell counts, these being medium-sized B or T lymphocytes with prominent nuclei $[165,166]$. B-cell (BPLL) and T-cell (T-PLL) have some clinical features and cell morphology in common. However, their biology and pathology are different and they are distinct entities [166]. Both B- and T-PLL are rare and account for approximately $2 \%$ of chronic lymphoid leukemias. Approximately $80 \%$ of the cases are of B-cell phenotype. PLL is a disease of the elderly, with median ages of about $65-70$ years. In contrast to HCL, the clinical course of PLL is progressive in the majority of patients, due to the resistance of the disease to conventional chemotherapy [167]. T-PLL has a more aggressive course, poorer response to chemotherapy and shorter median survival than B-PLL. Similarly to other indolent lymphoid malignancies, treatment does not seem to be indicated in asymptomatic patients with slowly progressive lymphocytosis. However, therapy is recommended in patients with symptomatic and progressive disease. In previous decades, splenectomy, splenic irradiation, leucapheresis, and 
alkylating agents used alone or in combination with other cytotoxic agents, have been used for the treatment of PLL. Purine nucleoside analogs have subsequently been used in the treatment of this disorder [169-173]. Palomera et al. [168] described the previously untreated patients with T- cell PLL, who received three cycles of 2-CdA and obtained CR. DCF $4 \mathrm{mg} / \mathrm{m}^{2}$ weekly or every two weeks have been used to treat small number of patients with B- or T-PLL with promising results. PR has been achieved in about half of the patients. The response rate in previously treated and untreated patients was similar. Several other reports have documented response to PNA in individual patients with PLL but long term follow-up is required to further evaluate the efficacy of these agents in this leukemia [169-173].

\subsection{Acute lymphoblastic leukemia}

Clofarabine is the most promising PNA in current clinical trials in pediatric and adult patients with hematological malignancies. During phase I studies the antileukemic activity at tolerable doses was well established thus several phase II clinical trials with clofarabine alone or in combination with other cytotoxic drugs have been recently conducted [174-176].

Jeha et al. [81] conducted a first pediatric trial of clofarabine in relapsed or refractory ALL and AML patients. In total, 17 patients with ALL and eight with AML were entered into this study. Clofarabine's doses ranged from 11.25 to $70 \mathrm{mg} / \mathrm{m}^{2}$ i.v. daily for five days. Five patients $(20 \%)$ achieved a CR, and $3(12 \%)$ achieved a PR, for an OR rate of $32 \%$. Based on the results of phase I clinical trials with clofarabine in pediatric patients with advanced leukamias, the MTD was established as $52 \mathrm{mg} / \mathrm{m}^{2}$ daily for five days. The DLT was reversible hepatotoxicity and skin rash at $70 \mathrm{mg} / \mathrm{m}^{2}$ i.v. per day for five days [81].

A phase II multicenter studies were performed in children with refractory or relapsed ALL or AML. The OR rate was $31 \%$ in ALL patients including six CR, four $\mathrm{CR}_{\mathrm{p}}$ (complete response with incomplete platelet recovery), and five PR. The median survival was 42 weeks for responding ALL patients. The most clofarabine- related adverse events were febrile neutropenia, diarrhea, nausea and vomiting, fever, skin rash, headache, elevation in liver enzymes and bilirubin, infusion-related flushing and anxiety [81].

In a phase II, multicenter study, 61 children with refractory or relapsed acute ALL received CAFdA at a dose of $52 \mathrm{mg} / \mathrm{m}^{2}$ i.v. over hours daily for five days, every two to six weeks [177]. The response rate was $30 \%$, consisting of seven $\mathrm{CR}$, five $\mathrm{CR}_{\mathrm{p}}$, and six $\mathrm{PR}$. The most common adverse events of grade 3-4 were febrile neutropenia, anorexia, hypotenstion, and nausea. Based on this study, clofarabine was approved by the US FDA in December 2004 for the treatment of pediatric patients with relapsed or refractory ALL after at least two prior chemotherapy regimens.

Recently Gidwani et al. [178] have published the results of the first report of successful remission induction in multiple relapsed ALL in a 9-year-old boy after combined treatment with CAFdA and arabinoside cytosine (ara-C).

Clofarabine was also used in combination with alkylating agents based on the results of preliminary studies showing synergistic cytotoxicity and inhibition of DNA repair for combining regimen. Eighteen patients with relapsed acute leukemias were treated with $\mathrm{CY}$ alone at the dose of $200 \mathrm{mg} / \mathrm{m}^{2}$ on day 0 , and with CAFdA at the dose of either $20 \mathrm{mg} / \mathrm{m}^{2}$ or $10 \mathrm{mg} / \mathrm{m}^{2}$ plus CY on day one 
[179]. Pharmacodynamic end points along with clinical results suggest usefulness of this combination strategy, whereas toxicity data suggest reduction of chemotherapeutic intensity

Nelarabine is a potent agent for treatment of hematologic malignancies with major efficacy in Tcell disorders [180,181]. Kurtzberg et al. [181] reported the clinical outcome of pediatric and adult patients with refractory hematological malignancies treated with nelarabine. The OR rate was $31 \%$, however this rate was $54 \%$ in the subgroups of patients with T-cell ALL who achieved a CR or PR after one or two cycles of nelarabine.

A phase II trial in 106 pediatric patients with relapsed or refractory T-cell malignancies revealed the effectiveness of nelarabine with an objective response rate of more than $50 \%$ in patients with first bone marrow relapse [182]. The initial nelarabine dose was $1.2 \mathrm{~g} / \mathrm{m}^{2}$ daily for five consecutive days every 21 days. The most significant side effects of nelarabine were neurologic complications.

In one pilot trial, a combination of nelarabine and FA was evaluated in 13 patients with a variety of refractory hematologic malignancies. Nine patients had indolent leukemias, including six with failed prior FA therapy, two patients had T-ALL, one had CML, and one had mycosis fungoides. Nelarabine was infused on days one, three and five at a dose of $1.2 \mathrm{~g} / \mathrm{m}^{2}$. On days three and five, FA at a dose of $30 \mathrm{mg} / \mathrm{m}^{2}$ was administered four hours before the nelarabine infusion. Seven patients (54\%) responded to this combination regimen achieving a PR or CR. Additionally, among six patients who were refractory to PNA (2-CdA or FA), four had remission and one achieved stable disease. This result may suggest the usefulness of nelarabine in diseases refractory to other PNA. Nelarabine was accepted by European Medical Agency (EMA) in June 2005 and the FDA granted accelerated approval for this this drug in October 2005 for treatment of refractory patients with T-ALL/T-LBL or in relapsed patients after at least two prior regimens [180]. This use is based on the induction of a CR.

Recently, Furman et al. [183] have presented spectacular results of forodesine in a phase IIa, multicenter trial in patients with advanced precursor T-ALL or T-PLL. Forodesine was administered intravenously, at the dose of $40 \mathrm{mg} / \mathrm{m}^{2}$ for five days weekly for total of six cycles. In nonresponders, after two cycles the dose was escalated to $90 \mathrm{mg} / \mathrm{m}^{2}$. At the last interim report, in total 34 pretreated patients an OR rate was $32.4 \%$ and a CR was achieved in $20.6 \%$. Time to progression for CR patients was 77 to 398 days and an OS were 77 to 459 days. In the analyzed group only two patients died. Authors concluded, that forodesine used as a single agent in relapsed or refractory T-cell leukemia occurred effective with minimal toxicity.

In the consecutive report forodesine was given at $40 \mathrm{mg} / \mathrm{m}^{2}$ for five days up to six cycles in three patients with refractory/relapsed T-ALL (two patients were prior and one post allogeneic hematopoietic stem cells transplantation) [184]. Up to publication of the study all three were alive and in CR with survival of $215+, 398+$ and 180+ days, respectively. In authors opinion, forodesine used in monotherapy can be effective before and after allogeneic HSCT with minimal toxicity and without affecting potential graft versus leukemia effect .

Preclinical data also showed an activity of forodesine in B-cell ALL. Results of those studies led to a phase I/II study. Up to now, the results of only two trials are available [185,186]. In the former one dose-escalation study in 6 patients with B-ALL is presented [185]. As many as five of them experienced hematological benefit, defined as a of tumor burden decrease. One of the patients, treated with a high dose of forodesine achieved a CR and two patients PRs. In the second study, 12 patients with refractory/relapsed B-ALL were treated with forodesine at the dose of $80 \mathrm{mg} / \mathrm{m}^{2}$. Two of patients 
achieved CR and there were no patients with a PR. The authors emphasize, that forodesine was welltolerated with preliminary evidence of activity as a single agent in B-ALL [1986].

\subsection{Non-Hodgkin lymphoma}

Non-Hodgkin lymphomas are a heterogenous group of entities with different clinical presentations and treatment outcomes depending on histopathological diagnosis. PNA showed remarkable activity in low grade non-Hodgkin lymphomas (LG-NHL) [187-196]. These agents have been found to be more effective in previously untreated LG-NHL than in patients refractory to or relapsing after conventional therapy. Recently, one phase II randomized study performed on previously treated LG-NHL patients showed that 2-CdA and FA give similar response rate and duration. [187]. In relapsed/refractory LGNHL patients 2-CdA induced durable responses with OR rates ranging from 32 to $76 \%$ and $\mathrm{CR}$ rates between $10 \%$ and $38 \%$ [188-192]. 2-CdA was even more active in previously untreated patients $[193,194]$. The OR rate was achieved in $64-88 \%$ and a CR in $25-32 \%$. 2-CdA was effective in combination with alkylating agents and MIT in the treatment of refractory or relapsed advanced stage of LG-NHL [195-197].

Lower doses of 2-CdA ( $5 \mathrm{mg} / \mathrm{m}^{2} /$ week $)$ have been also investigated both in monotherapy [205198] and in combination with MIT [199,200]. The results proved that in indolent lymphoid malignancies, the reduced dose of cladribine is highly active and possibly better tolerated than this drug administered in standard dose.

FA is also an active agent in LG-NHL. In two large phase III clinical studies by Zinzani et al. [201] and Hagenbeek et al. [202] with FA used as a first line treatment in LG-NHL patients, the 84-68\% of ORs and $38-47 \%$ of CRs have been demonstrated. Also in relapsed/refractory LG-NHL patients both FA and 2-CdA induced durable responses, with OR rates about $70 \%$ and high $\mathrm{CR}$ rates $(48 \%$ ad $38 \%$, respectively) [203].

A randomized phase III study of FA versus traditional CY, vincristine and prednisone (COP) regimen in patients with recurrent LG-NHL has been also reported [204]. No significant difference either in survival or in a response rate in FA (OR 64\%, CR 9\%) versus COP (OR 52\%, CR 7\%) arms was observed.

FM (FA- + MIT) regimen was highly effective in early stages of mucosa-associated lymphoid tissue (MALT) lymphoma, with projected $100 \%$ of a 5-year OS [205]. Good response to 2-CdA in MALT lymphoma patients was also observed, Jagger et al. [206] reported results of 2-CdA treatment in 25 previously untreated patients with 34\% CR rate, including 100\% CRs in patients with gastric and $13 \%$ with extra-gastric disease localization.

Robak et al [207] presented the updated results of a study evaluating the feasibility, efficacy and toxicity of the cladribine combined with MIT and CY (CMC regimen) in patients with refractory or relapsed NHL. Thirty six patients, 13 with mantle cell lymphoma (MCL), eight with diffuse large Bcell lymphoma (DLBCL), five with follicular lymphoma (FL), three with small lymphocytic lymphoma (SLL), and four with T-cell lymphoma were enrolled to the study. The CMC protocol consisted of 2-CdA at a dose of $0.12 \mathrm{mg} / \mathrm{kg}$ in a 2-hour infusion on days one through three, MIT 10 $\mathrm{mg} / \mathrm{m}^{2}$ i.v. on day one and CY $650 \mathrm{mg} / \mathrm{m}^{2}$ i.v. on day one. The CMC courses were repeated at 4-week intervals. Thirty three patients were available for evaluation of response. Overall response rate was 
$58 \%$ (95\%CI, 41-75\%). The median failure-free survival (FFS) was five months (range, 2 - 17 months). The median OS for the entire group was nine months (range, 0.1 - 77 months). There was a significant difference in OS between responders and nonresponders after CMC therapy (log rank test, $\mathrm{p}=0.015)$. When different disease status before $\mathrm{CMC}$ treatment was considered, a trend toward longer survival of recurrent patients was observed ( $\log$ rank test, $p=0.08)$. The study showed that the CMC regimen is effective salvage therapy with acceptable toxicity in heavily pretreated patients with NHL including MCL and DLBCL.

Cladribine has been reported to be active as the first-line therapy or in first relapse among patients with MCL achieving a response rate of 58\% [201]. Rummel et al. [200] reported increased efficacy of the combination treatment with reduced-dose of 2-CdA and MIT in previously untreated or relapsed patients with MCL. They achieved a response rate of $100 \%$ with a $44 \%$ of CR rate. High response rates to the combined chemotherapy in MCL patients confirm its superiority to monotherapy.

Another purine analog, fludarabine, has been also shown to be effective in the treatment of lowgrade lymphomas, and in particular of MCL [208-210]. Similarly to 2-CdA, FA seems to be more active if it is combined with CY or CY and MIT. The German Low-Grade Lymphoma Study Group obtained an OR of $46 \%$ in relapsed or refractory MCL patients receiving the combination of FA, CY and MIT [215]. Recent studies indicate that the addition of monoclonal antibody, rituximab, increases the clinical effectiveness of standard chemotherapy [205-208]. Forstpointner at al. [208] achieved a higher overall response rate $(79 \%$ vs $58 \%)$, a higher complete remission rate $(33 \% \mathrm{vs} 13 \%)$, and a superior OS at two years ( $90 \%$ vs $70 \%$ ) in the relapsed/refractory LG-NHL patients treated with rituximab combined with chemotherapy (R-FMC) compared to those received the chemotherapy alone (FMC) . We have evaluated the feasibility, efficacy, and toxicity of combined regimens that consisted of either rituximab plus cladribine (2-CdA) (the RC regimen) or RC plus CY (the RCC regimen) in the treatment of patients with heavily pretreated, indolent lymphoid malignancies [211]. Fifty-four adult patients with recurrent or refractory, low-grade NHL were treated according to the RC/RCC regimens. Thirty-three patients with CLL, 12 patients with LG-NHL and nine patients with MCL entered the study. Thirty-three patients (61\%) had recurrent disease after prior therapy, and 21 patients (39\%) had refractory disease. Thirty-one patients were treated on the $\mathrm{RC}$ regimen, and 23 patients were treated on the RCC regimen. Six patients (11\%) achieved a CR, and 33 patients $(60 \%)$ achieved a PR. The RC and RCC regimens were highly effective and well tolerated modalities of treatment in heavily pretreated patients with indolent lymphoproliferative disorders.

\section{Side Effects and Tolerability}

The tolerability profile of PNA is distinguishable from that of other cytotoxic agents. However, bone marrow suppression with prolonged thrombocytopenia, neutropenia and anemia is a common complication of the PNA. Moreover, treatment with PNA leads to a decrease in the CD4+/CD8+ ratio for an extensive period of time exceeding even 24 months [212]. In consequence, infections, including opportunistic ones, are frequent events and infections with fatal outcome have been reported. Infections are the most frequent side effect in patients treated with PNA [212-214]. The most common infection complications arising from PNA toxicity are respiratory tract infections with bacterial pathogens and unexplained fever [213-226]. However, several studies revealed the emergence of new 
pathogens typically associated with T-cell dysfunction including Pneumocystis carinii, Listeria monocytogenes, Cytomegalovirus, Herpes simplex and Varicella zoster virus, as well as Mycobacterium tuberculosis [214-219]. T-cell depletion and neutropenia are well-known factors predisposing to infection. They may occur as a consequence of extensive leukemic bone marrow involvement and are worsened by PNA therapy.

Reduction in myelosuppression and granulocytopenia may be achieved with the prophylactic use of growth factors following the PNA cycles. O'Brien et al. [220] showed that prophylactic administration of granulocyte-colony stimulating factor (G-CSF) to patients treated with FA may reduce the incidence of pneumonia, but does not interfere with the infections. G-CSF prophylaxis ameliorated neutropenia, allowed delivery of therapy on time and reduced the incidence of pneumonia especially in high-risk patients treated with FA [220]. It should also be remembered that prophylactic administration of hemopoietic growth factors may greatly increase the cost of treatment. In our department G-CSF is applied only in patients with CLL treated with PNA when neutropenia is lower than $1 \times 10^{9} / \mathrm{L}$ and severe infection develops.

As an alternative some authors are in favor of prophylaxis with antibacterial and antiviral agents in patients treated with PNA alone and especially in combination with other agents [221, 222]. This approach is intended to reduce the incidence of opportunistic infections. Therefore, some investigators recommend routine prophylaxis with trimethoprim/sulfamethoxole or pentamidine and acyclovir or valacyclovir, which can account for the lack of serious infections caused by Herpes simplex and Varicella zoster viruses, Pneumocystis carini and Listeria monocytogenes [223].

Some reports suggest that PNA may induce autoimmune hemolytic anemia (AIHA), especially in patients with CLL despite the reduction in leukemic clone [224]. However, in our randomized study the difference in frequence of AIHA in patients treated with 2-CdA or Chl was not statistically significant [132,133]. Leporrier et al. [135] reported true AIHA only in 3\% of the patients treated with CHOP (cyclophosphamide, hydroxyrubicin, vincristine, prednisone), $1.5 \%$ treated with CAP (cyclophosphamide, adriamycin, prednisone) and 1.5\% treated with FA. Thus, the results of prospective multicentre randomized studies do not support the conclusion that the risk of AIHA is higher in the CLL patients treated with PNAs than in patients treated with Chl or other alkylating agents based regimens.

Prolonged immunosuppression related to the PNA treatment may increase the risk of secondary malignancies. Some authors observed secondary MDS/AML and other cancers in patients treated with these agents [225-229]. However, a retrospective analysis performed by Cheson et al. [228] in which they compared secondary tumours in CLL patients treated with FA has shown that this agent does not increase the risk of secondary neoplasms. In our randomized study comparing 2-CdA with Chl in previously untreated patients with CLL we observed secondary malignancies only in two patients treated with 2-CdA and in one patient treated with $\mathrm{Chl}$.

Recently, we have analyzed whether the treatment with 2-CdA during the course of CLL had an impact on the subsequent occurrence of either secondary solid tumors or Richer's syndrome (RS) [229]. There were 1,487 eligible patients, 251 treated only with 2-CdA, 913 treated only with alkylating agents (AA) based regimens and 323 treated with both 2-CdA and AA. Fifty eight patients with secondary cancer or Richter's syndrome were observed. The differences between 2-CdA, AA and $2-\mathrm{CdA}+\mathrm{AA}$ treated group were not significant $(\mathrm{P}>0.05)$. Only lung cancer occurred significantly 
more frequently in the $2-\mathrm{CdA}(4 \%)$ treated group as compared to only one patient $(1.9 \%)$ treated with AA ( $p=0.001$ and $p<0.05$ respectively). On the basis of these observations 2-CdA does not seem to increase the risk of secondary malignancies except in case of the lung cancer.

\section{Conclusions}

The purine nucleoside analogues, cladribine, fludarabine and pentostatin, share similar structure and mechanism of cytotoxic action, such as induction of apoptosis. However, they exhibit also significant differences especially in their interactions with enzymes involved in adenosine and deoxyadenosine metabolism activity. The main mechanism of PNA cytotoxicity is apoptosis which can be induced and mediated by indirect DNA damage, activation of caspases or by triggering of caspase-independent pathway. Several in vitro and in vivo studies have shown a synergy between PNAs and other chemotherapeutic agents and monoclonal antibodies active in hematological malignancies. PNAs alone or in combinations with other agents are the drugs of choice in HCL, CLL and NHL. More recently, a novel group of PNAs has been developed. These agents include CAFdA, nelarabine and forodesine and they are currently under investigation in pre-clinical and clinical studies. Their active forms, metabolic properties and mechanism of action of nelarabine and forodesine are different from other PNA. All these three drugs have shown promising activity in patients with relapsed and refractory ALL. Clofarabine was approved for the treatment of relapsed or refractory ALL in the third line of treatment. Nelarabine is recommended for T-ALL and T-cell lymphoblastic lymphoma (TLBL). However, the use of this drug is limited by potentially severe neurotoxicity. Forodesine is a new drug with mechanism of action different than the other PNA and it has shown activity in relapsed and refractory T- and B-cells leukemias and CTCL. Great hopes are currently set on the use of these drugs in the treatment of lymphoid malignancies in adult and in pediatric patients.

\section{Acknowledgements}

This work was supported in part by the grant from the Medical University of Lodz (No 503-1093-1) and by the Foundation for the Development of Diagnostics and Therapy, Warsaw, Poland. The authors have no conflicts of interest that are directly relevant to the content of this review. We thank Professor Zygmunt Kazimierczuk, Institute of Chemistry, Agricultural University and Medical Research Center, Polish Academy of Sciences, Warsaw, Poland for correction of this manuscript.

\section{List of Abbreviations}

$\begin{array}{ll}\text { 2-CdA- } & \text { 2-chloro-2'-deoxyadenosine; } \\ & \text { 2-chloro-9-(2'-deoxy- } \beta \text {-D-ribofuranosyl)-adenine; cladribine } \\ \text { 5'-NT- } & \text { 5'-nucleotidase } \\ \text { AA- } & \text { aplastic anemia } \\ \text { ADA- } & \text { adenine deaminase } \\ \text { Ado- } & \text { adenosine } \\ \text { AIF- } & \text { apoptosis-inducing factor }\end{array}$




\begin{tabular}{|c|c|}
\hline AIHA- & autoimmune hemolytic anemia \\
\hline ALL- & acute lymphoblastic leukemia \\
\hline AML- & acute myeloid leukemia \\
\hline APAF-1- & apoptotic protease activating factor \\
\hline Ara-C- & 9- $\beta$-D-arabinofuranosylcytosine; cytarabine \\
\hline Ara-G- & 9- $\beta$-D-arabinofuranosylguanine; nelarabine \\
\hline AUC- & area under the concentration-time curve \\
\hline BCX-1777- & immucillin $\mathrm{H}$; forodesine \\
\hline CAFdA- & 2-chloro-2'-fluoro-2'-deoxyadenosine; \\
\hline & 2-chloro-9-(2'-deoxy-2'-fluoro- $\beta$-D-arabinofuranosyl)-adenine; clofarabine \\
\hline Chl- & chlorambucil \\
\hline CLL- & chronic lymphocytic leukemia \\
\hline $\mathrm{C}_{\max }-$ & maximum plasma concentration \\
\hline CML-BP- & chronic myelogenous leukemia blast phase \\
\hline CR- & complete response \\
\hline CTCL- & cutaneous T-cell lymphoma \\
\hline $\mathrm{CY}-$ & cyclophosphamide \\
\hline dAdo- & deoxyadenosine \\
\hline DCF- & 2'-deoxyocoformycin; pentostatin \\
\hline $\mathrm{dCK}-$ & deoxycytidine kinase \\
\hline dGK- & deoxyguanine kinase \\
\hline dGuo- & 2'-deoxyguanosine \\
\hline DLBCL- & diffusse large B-cell lymphoma \\
\hline DLT- & dose limiting toxicity \\
\hline DNMT1-DNA & methylotransferase \\
\hline DNR- & daunorubicin \\
\hline FA- & 2-fluoroadenosine; 2-fluoro-9-( $\beta$-D-arabinofuranosyl)-adenine; fludarabine \\
\hline FAMP- & fludarabine monophosphate \\
\hline FC- & fludarabine + cyclophosphamide \\
\hline FCM- & fludarabine + cyclophosphamide + mitoxantrone \\
\hline FL- & follicular lymphoma \\
\hline FM- & fludarabine + mitoxantrone \\
\hline FMC- & fludarabine + mitoxantrone + cyclophosphamide \\
\hline G-CSF- & granulocyte colony stimulating factor \\
\hline HCL- & hairy cell leukaemia \\
\hline hCNT- & human concentrative nucleoside transporter \\
\hline hENT- & human equilibrative nucleoside transporter \\
\hline LG-NHL- & low grade non-Hodgkin's lymphoma \\
\hline MALT- & mucosa associated lymphoid tissue lymphoma \\
\hline MCL- & mantle cell lymphoma \\
\hline MRD- & minimal residual disease \\
\hline MDS- & myelodysplastic syndrome \\
\hline
\end{tabular}




$\begin{array}{ll}\text { MIT- } & \text { mitoxantrone } \\ \text { MTD- } & \text { maximum tolerated dose } \\ \text { NHL- } & \text { non-Hodgkin's lymphoma } \\ \text { OR- } & \text { overall response } \\ \text { OS- } & \text { overall survival } \\ \text { PARP- } & \text { poly ADP-ribose polymerase } \\ \text { PFS- } & \text { progression free survival } \\ \text { PLL- } & \text { prolymphocytic leukemia } \\ \text { PNA- } & \text { purine nucleoside analogues } \\ \text { PNP- } & \text { purine nucleoside phosphorylase } \\ \text { PR- } & \text { partial response } \\ \text { RCC- } & \text { rituximab + cladribine }+ \text { cyclophosphamide } \\ \text { R-FC- } & \text { rituximab + fludarabine }+ \text { cyclophosphamide } \\ \text { RR- } & \text { ribonucleotide reductase } \\ \text { SLL- } & \text { small lymphocytic lymphoma } \\ T_{1 / 2}- & \text { half life time } \\ V_{d^{-}} & \text {value of distribution } \\ \text { WM- } & \text { Waldenström macroglobulinemia }\end{array}$

\section{References}

1. Tallman, M.S.; Hakimian, D.; Variakojis, D.; Koslow, D.; Sisney, G.A.; Rademaker, A.W.; Rose, E.; Kaul, K. A single cycle of 2-chlorodeoxyadenosine results in complete remission in the majority of patients with hairy cell leukemia. Blood 1992, 80, 2203-2209.

2. Robak, T.; Korycka, A.; Kasznicki, M.; Wrzesień-Kuś, A.; Smolewski, P. Purine nucleoside analogues for the treatment of hematological malignancies: Pharmacology and clinical applications. Curr. Cancer Drug Targets 2005, 5, 421-444.

3. Johnson, S.A. Nucleoside analogues in the treatment of hematological malignancies. Expert Opin. Pharmacother. 2001, 2, 929-943.

4. Robak, T.; Kasznicki, M. Alkylating agents and nucleoside analogues in the treatment of B-cell chronic lymphocytic leukemia. Leukemia 2002, 16, 1015-1027.

5. Robak, T.; Lech-Maranda, E.; Korycka, A.; Robak, E. Purine nucleoside analogs as immunosuppressive ans antineoplastic agents: mechanism of action and clinical activity. Curr. Med. Chem. 2006, 13, 3165-3189.

6. Pettit, A.R. Mechanism of action of purine analogues in chronic lymphocytic leukemia. Br. J. Haematol. 2003, 121, 692-702.

7. Robak, T. Current treatment options in hairy cell leukemia and hairy cell leukemia variant. Cancer Treat. Rev. 2006, 32, 365-376.

8. Pastor-Anglada, M.; Molina-Arcas, M.; Casado, F.J.; Bellosillo, B.; Colomer, D.; Gil, J. Nucleoside transporters in chronic lymphocytic leukemia. Leukemia 2004, 18, 385-393.

9. Robak, T. Recent progress in the management of chronic lymphocytic leukemia. Cancer Treat. Rev. 2007, 33, 710-728. 
10. Kalinka-Warzocha, E.; Wajs, J.; Lech-Maranda, E.; Ceglarek, B.; Holowiecki, J.; Federowicz, I.; Walewski, J.; Czyz, J.; Robak, T.; Warzocha, K. Polish Lymphoma Research Group. Randomized comparison of cladribine alone or in combination with cyclophosphamide, and cyclophosphamide, vincristine and prednisone in previously untreated low-grade B-cell nonHodgkin lymphoma patients: final report of the Polish Lymphoma Research Group. Cancer 2008, 113, 367-375.

11. Zinzani, P.L. Non-Hodgkin's lymphoma: the evolving role of purine analogues. Best Pract. Res. Clin. Haematol. 2002, 15, 505-516.

12. Hellmann, A.; Lewandowski, K.; Zaucha, J.M.; Bieniaszewska, M.; Halaburda, K.; Robak, T. Effect of a 2-hour infusion of 2-chlorodeoxyadenosine in the treatment of refractory or previously untreated Waldenström's macroglobulinemia. Eur. J. Haematol. 1999, 63, 35-41.

13. Johnson, S.A.; Oscier, D.G.; Leblond, V. Waldenstrom's macroglobulinaemia. Blood Rev. 2002, $16,175-184$.

14. Evens, A.M.; Gartenhaus, R.B. Treatment of T-cell non-Hodgkin's lymphoma. Curr. Treat Options Oncol. 2004, 5, 289-303.

15. Korycka, A.; Lech-Maranda, E.; Robak, T. Novel purine nucleoside analogues for hematological malignancies. Recent Patents AntiCancer Drug Discov. 2008, 3, 123-136.

16. Parker, W.B.; Secrist, J.A. $3^{\text {rd }}$; Waud, W.R. Purine nucleoside antimetabolites in development for the treatment of cancer. Curr. Opin. Investig. Drugs 2004, 5, 592-596.

17. Faderl, S.; Gandhi, V.; Keating, M.J.; Jeha, S.; Plunkett, W.; Kantarjian, H.M. The role of clofarabine in hematologic and solid malignancies--development of a next-generation nucleoside analog. Cancer 2005, 103, 1985-1995.

18. Pui, C.H.; Jeha, S.; Kirkpatrick, P. Clofarabine. Nat. Rev. Drug Discov. 2005, 4, 369-370.

19. Roecker, A.M.; Allison, J.C.; Kisor, D.F.; Nelarabine: efficacy in the treatment of clinical malignancies. Future Oncol. 2006, 2, 441-448.

20. Prus, K.L.; Averett, D.R.; Zimmerman, T.P. Transport and metabolism of 9-beta-Darabinofuranosylguanine in a human T-lymphoblastoid cell line nitrobenzylthioinosine-sensitive and - insensitive influx. Cancer Res. 1990, 50, 1817-1821.

21. Kisor, D.F. Nelarabine use in leukemias. Drugs Today 2006, 42, 455-465.

22. Balakrishnan, K.; Nimmanapalli, R.; Ravandi, F.; Keating, M.J.; Gandhi, V. Forodesine, an inhibitor of purine nucleoside phosphorylase, induces apoptosis in chronic lymphocytic leukemia cells. Blood 2006, 108, 2392-2398.

23. Korycka, A.; Błoński, J.Z.; Robak, T. Forodesine (BCX-1777, Immucillin H)- a new purine nucleoside analogue: mechanism of action and potential clinical application. Mini Rev. Med. Chem. 2007, 7, 976-983.

24. Leung, G.; Tse, Ch-M. The role of mitochondrial and plasma mermbrane nucleoside transporters in drug toxicity. Expert Opin Drug Metab Toxicol. 2007, 3, 1-14.

25. de Wolf, C.; Jansen, R.; Yamaguchi, H.; de Haas, M.; van de Wetering, K.; Wijnholds, J.; Beijnen, J.; Borst, P. Contribution of the drug transporter ABCG2 (breast cancer resistance protein) to resistance against anticancer nucleosides. Mol Cancer Ther. 2008, 7, 3092-3102.

26. Takenaka, K.; Morgan, J.A.; Scheffer, G.L.; Adachi, M.; Stewart, C.F.; Sun, D.; Leggas, M.; Ejendal, K.F.; Hrycyna, C.A.; Schuetz, J.D. Substrate overlap between Mrp4 and Abcg2/Bcrp 
affects purine analogue drug cytotoxicity and tissue distribution. Cancer Res. 2007, 67, 69656972.

27. Krishnamurthy, P.; Schwab, M.; Takenaka, K.; Nachagari, D.; Morgan, J.; Leslie, M.; Du, W.; Boyd, K.; Cheok, M.; Nakauchi, H.; Marzolini, C.; Kim, R.B.; Poonkuzhali, B.; Schuetz, E.; Evans, W.; Relling, M.; Schuetz, J.D. Transporter-mediated protection against thiopurine-induced hematopoietic toxicity. Cancer Res. 2008, 68, 4983-4989.

28. Molina-Arcas, M.; Marce, S.; Villamor, N.; Huber-Ruano, I.; Casado, F.J.; Bellosillo, B.; Montserrat, E.; Gil, J.; Colomer, D. Equilibrative nucleoside transporter-2 (hENT2) protein expression correlates with ex vivo sensitivity to fludarabine in chronic lymphocytic leukemia (CLL) cells. Leukemia 2005, 19, 64-68.

29. Molina-Arcas, M.; Bellosillo, B.; Casado, F.J.; Montserrat, E.; Gil, J.; Colomer, D.; PastorAnglada, M. Fludarabine uptake mechanisms in B-cell chronic lymphocytic leukemia. Blood 2003, 101, 2328-2334.

30. Mackey, J.R.; Galmarini, C.M.; Graham, K.A.; Joy, A.A.; Delmar, A.; Dabbagh, L.; Glubrecht, D.; Jewell, L.D.; Lai, R.; Lang, T.; Hanson, J.; Young, J.D.; Merle-Beral, H.; Binet, J.L.; Cass, C.E.; Dumontet, C. Quantitative analysis of nucleoside transporter and metabolism gene expression in chronic lymphocytic leukemia (CLL): identification of fludarabine-sensitive and insensitive populations. Blood 2005, 105, 767-774.

31. Rodriquez, C.O.; Mitchell, B.S.; Ayres, M.; Eriksson, S.; Gandhi, V. Arabinosylguanine is phosphorylated by both cytoplasmic deoxycytidine kinase and mitochondrial deoxyguanosine kinase. Cancer Res. 2002, 62, 3100-3105.

32. Van den Neste, E.; Cardoen, S.; Offner, F.; Bontemps, F. Old and new insights into the mechanisms of action of two nucleoside analogs active in lymphoid malignancies: fludarabine and cladribine (review). Intern. J. Oncol. 2005, 27, 1113-1124.

33. Adkins, J.C.; Peters, D.H.; Markham, A. Fludarabine. An update of its pharmacology and use in the treatment of haematological malignancies. Drugs 1997, 53, 1005-1037.

34. Malspeis, L.; Grever, M.R.; Staubus, A.E.; Young, D. Pharmacokinetics of 2-F-ara-A (9-beta-Darabinofuranosyl-2-fluoroadenine) in cancer patients during the phase I clinical investigation of fludarabine phosphate. Semin. Oncol. 1990, 17, 18-32 .

35. Hutton, J.J.; Von Hoff, D.D.; Kuhn, J.; Phillips, J.; Hersh, M.; Clark, G. Phase I clinical investigation of 9-beta-D-arabinofuranosyl-2-fluoroadenine 5'-monophosphate (NSC 312887), a new purine antimetabolite. Cancer Res. 1984, 44, 4183-4186.

36. Foran, J.M.; Oscier, D.; Orchard, J.; Johnson, S.A.; Tighe, M.; Cullen, M.H.; de Takats, P.G.; Kraus, C.; Klein, M.; Lister, TA. Pharmacokinetic study of single doses of oral fludarabine phosphate in patients with "low-grade" non-Hodgkin's lymphoma and B-cell chronic lymphocytic leukemia. J. Clin. Oncol. 1999, 17, 1574-1579.

37. Boogaerts, M.A. Oral fludarabine therapy in chronic lymphocytic leukemia--increased convenience. Hematology J. 2004, 5, 31-37.

38. Beutler, E. Cladribine (2-chlorodeoxyadenosine). Lancet 1992, 340, 952-956.

39. Carson, D.A.; Wasson, D.B.; Taetle, R.; Yu, A. Specific toxicity of 2-chlorodeoxyadenosine toward resting and proliferating human lymphocytes. Blood 1983, 62, 737-743. 
40. Seto, S.; Carrera, C.J.; Kubota, M.; Wasson, D.B.; Carson, D.A. Mechanism of deoxyadenosine and 2-chlorodeoxyadenosine toxicity to nondividing human lymphocytes. J. Clin. Invest. 1985, 75, 377-383.

41. Griffig, J.; Koob, R.; Blakley, R.L.; Mechanism of inhibition of DNA synthesis by 2chlorodeoxyadenosine in human lymphoblastic cells. Cancer Res. 1989, 49, 6923-6928.

42. Robertson, L.E.; Chubb, S.; Meyn, R.E.; Story, M.; Ford, R.; Hittelman, W.N.; Plunkett, W. Induction of apoptotic cell death in chronic lymphocytic leukemia 2-chloro-2'-deoxyadenosine and 9- $\beta$-D-arabinosyl-2-fluoroadenine. Blood 1993, 81, 143-150.

43. Carson, D.A.; Carrera, C.J.; Wasson, D.B.; Yamanaka, H. Proogrammed cell death and adenine deoxynucleotide metabolism in humans lymphocytes. Adv. Enzyme Regul. 1988, 27, 395-404.

44. Kawasaki, H.; Carrera, C.J.; Piro, L.D.; Saven, A.; Kipps, T.J.; Carson, D.A. Relationship of deoxycytydine kinase and cytoplasmic 5'nucloetidase to the chemothrapeutic efficacy of 2chlorodeoxyadenosine. Blood 1993, 81, 597-601.

45. Marzo, I.; Perez-Gala, P.; Rubio-Felix, D.; Anel, A.; Naval, J. Cladribine induces apoptosis in human leukemia cells by caspase-dependent and -independent pathways acting on mitochondra. Biochemistry 2001, 359, 537-546.

46. Nomura, Y.; Inanami, O.; Takahashi, K.; Matsuda, A.; Kuwabara, M. 2-Chloro-2'deoxyadenosine induces apoptosis through the Fas/Fas ligand pathway in human leukemia cell line MOLT-4. Leukemia 2000, 14, 299-306.

47. Johnston, J.B.; Daeninck, P.; Verburg, L.; Lee, K.; Williams, G.; Israels, L.G.; Mowat, M.R.; Begleiter, A. P53, mdm-2, bax and bcl-2 and drug resistance in chronic lymphocytic leukemia. Leuk. Lymphoma 1997, 26, 425-449.

48. Genini, D.; Budihardjo, I.; Plunkett, W.; Wang, X.; Carrera, C.J.; Cottam, H.B.; Carson, D.A.; Leoni, L.M. Nucleotide requirements for the in vitro activation of the apoptosis protein-activating factor-1-mediated caspase pathway. J. Biol. Chem. 2000, 275, 29-34.

49. Grutter, M.G. Caspases: key players in programmed cell death. Curr. Opinion Struct. Biol. 2000, 10, 649-655.

50. Bosanquet, A.G.; Sturm, I.; Wieder, T.; Essmann, F.; Bosanquet, M.I.; Head, D.J.; Dörken, B.; Daniel, P.T. Bax expression correlates with cellular drug sensitivity to doxorubicin, cyclophosphamide and chlorambucil but not fludarabine, cladribine or corticosteroids in B-cell chronic lymphocytic leukemia. Leukemia 2002, 16, 1035-1044.

51. Klopfer, A.; Hasenjager, A.; Belka, C.; Schulze-Osthoff, K.; Dorken, B.; Daniel, P. Adenine deoxynucleotides fludarabine and cladribine induces apoptosis in a CD95/Fas receptor, FADD and caspase-8- independent manner by activation of the mitochondrial cell death pathway. Oncogene 2004, 16, 9408-9418.

52. Johnson, S.A. Clinical pharmacokinetics of nucleoside analogues. Focus on haematological malignancies. Clin. Pharm. 2000, 39, 5-26.

53. Saven, A.; Cheung, W.K.; Smith, I.; Moyer, M.; Johannsen, T.; Rose, E.; Gollard, R.; Kosty, M.; Miller, W.E.; Piro, L.D. Pharmacokinetics study of oral and bolus intravenous 2chlorodeoxyadenosine in patients with malignancy. J. Clin. Oncol. 1996, 14, 978-983. 
54. Liliemark, J.; Albertioni, F.; Hassan, M.; Juliusson, G. One the bioavailability of oral and subcutaneous 2-chloro-2'-deoxyadenosine in humans: alternative routes of administration. J. Clin. Oncol. 1992, 10, 1514-1518.

55. Robak, T.; Błasińska-Morawiec, M.; Krykowski, E.; Hansz, J.; Komarnicki, M.; Kazimierczak, M.; Konopka, L.; Maj, S.; Hellmann, A.; Zaucha, J.M.; Urasiński, L.; Zdziarska, B.; KotlarekHaus, S.; Usnarska-Zubkiewicz, L.; Kuratowska, Z.; Dwilewicz-Trojaczek, J.; Hołowiecki, J.; Krawczyk-Kulis, M.; Grieb, P. 2-chlorodeoxyadenosine (2-CdA) in 2-hour versus 24-hour intravenous infusion in the treatment of patients with hairy cell leukemia. Leuk. Lymphoma 1996, 22, 107-111.

56. Liliemark, J.; Juliusson, G. On the pharmacokinetics of 2-chloro-2'-deoxyadenosine in humans. Cancer Res. 1991, 51, 5570-5572.

57. Albertioni, F.; Pettersson, B.; Reichelová, V.; Juliusson, G.; Liliemark, J. Analysis of 2-chloro-2'deoxyadenosine in human blood plasma and urine by high-performance liquid chromatography using solid-phase extraction. The Drug Monit 1994, 16, 413-418.

58. Liliemark, J.; Pettersson, B.; Juliusson, G. Determination of 2-chloro-2'-deoxyadenosine in human plasma. Biomed. Chromatogr. 1991, 5, 262-264.

59. Lindemalm, S.; Savic, R.M.; Karlsson, M.O.; Liliemark, J.; Juliusson, G.; Albertioni, F. Application of population pharmacokinetics to cladribine. BMC Pharmacol. 2005, 9,5:4.

60. Robak, T.; Korycka, A.; Robak, E. Older and new formulations of cladribine. Pharmacology and clinical efficacy in hematological malignancies. Recent Patents Anticancer Drug Discov. 2006, 1 , 23-38.

61. Juliusson, G.; Heldal, D.; Hippe, E.; Hedenus, M.; Malm, C.; Wallman, K.; Stolt, C.M.; Evensen, S.A.; Albertioni, F.; Tjønnfjord, G. Subcutaneous injections of 2-Chlorodeoxyadenosine for symptomatic hairy cell leukemia. J. Clin. Oncol. 1995, 13, 989-995.

62. Aldinucci, D.; Poletto, D.; Lorenzon, D.; Nanni, P.; Degan K.O.; Rapana,B.; Pinto, A.; Gattei, V. CD26 expression correlates with a reduced sensitivity to 2'-deoxycoformycin-induced growth inhibition and apoptosis in T-cell leukemia/lymphomas. Clin. Cancer Res. 2004, 10, 508-520.

63. Brogden, R.N.; Sorkin, E.M. Pentostatin: A review of its pharmacodynamic and pharmacokinetic properties, and therapeutic potential in lymphoproliferative disorders. Drugs 1993, 4, 652-677.

64. Niitsu, N.; Yamaguchi, Y.; Umeda, M.; Honma, Y. Human monocytoid leukemia cells are highly sensitive to apoptosis induced by 2'-deoxycoformycin and 2'-deoxyadenosine: association with dATP-dependent activation of caspase-3. Blood 1998, 92, 3368-3375.

65. Venner, P.M.; Glazer, R.I.; Blatt, J.; Sallan, S.; Rivera, G.; Holcenberg, J.S.; Lipton, J.; Murphy, S.B.; Poplack, D.G. Levels of 2'-deoxycoformycin, adenosine, and deoxyadenosine in patients with acute lymphoblastic leukemia. Cancer Res. 1981, 41, 4508-4511.

66. Staubus, A.E.; Weinrib, A.B.; Malspeis, L. An enzymatic kinetic method for the determination of 2'-deoxycoformycin in biological fluids. Biochem. Pharmacol. 1984, 33, 1633-1637.

67. Smyth, J.F.; Paine, R.M.; Jackman, A.L.; Harrap, K.R.; Chassin, M.M.; Adamson, R.H.; Johns, D.G. The clinical pharmacology of the adenosine deaminase inhibitor 2'-deoxycoformycin. Cancer. Chemother. Pharmacol. 1980, 5, 93-101.

68. Major, P.P.; Agarwal, R.P.; Kufe, D.W. Clinical pharmacology of deoxycoformycin. Blood 1981, $58,91-96$. 
69. Grever, M.R.; Siaw, M.F.; Jacob, W.F.; Neidhart, J.A.; Miser, J.S.; Coleman, M.S.; Hutton, J.J.; Balcerzak, S.P. The biochemical and clinical consequences of 2'-deoxycoformycin in refractory lymphoproliferative malignancy. Blood 1981, 57, 406-417.

70. Pui, C.H.; Jeha, S.; Kirkpatrick, P. Clofarabine. Nat. Rev. Drug Discov. 2005, 4, 369-370.

71. Lindemalm, S.; Liliemark, J.; Juliusson, G.; Larsson, R.; Albertioni, F. Cytotoxicity and pharmacokinetics of cladribine metabolite, 2-chloroadenine in patients with leukemia. Cancer Lett. 2004, 210, 171-177.

72. Bonate, P.L.; Arthaud, L.; Cantrell, W.R.Jr.; Stephenson, K.; Secrist, J.A. ${ }^{\text {rd }}$; Weitman, S. Discovery and development of clofarabine: a nucleoside analogue for treating cancer. Nat. Rev. Drug Discov. 2006, 5, 855-863.

73. Reichelova, V.; Liliemark, J.; Albertioni, F. Liquid chromatographic study of acid stability of 2chloro-2'-arabino-fluoro-2'-deoxyadenosine, 2-chloro-2'-deoxy-adenosine and related analogues. J. Pharm. Biomed. Anal. 1995, 13, 711-714.

74. King, K.M.; Damaraju, V.L.; Vickers, M.F.; Yao, S.Y.; Lang, T.; Tackaberry, T.E.; Mowles, D.A.; Ng, A.M.; Young, J.D.; Cass, C.E. A comparison of the transportability, and its role in cytotoxicity, of clofarabine, cladribine, and fludarabine by recombinant human nucleoside transporters produced in three model expression systems. Mol. Pharmacol. 2006, 69, 346-353.

75. Lotfi, K.; Månsson, E.; Spasokoukotskaja, T.; Pettersson, B.; Liliemark, J.; Peterson, C.; Eriksson, S.; Albertioni, F. Biochemical pharmacology and resistance to 2-chloro-2'-arabino-fluoro-2'deoxyadenosine, a novel analogue of cladribine in human leukemic cells. Clin. Cancer Res. 1999, 5, 2438-2444.

76. Zhang, Y.; Secrist, J.A. $3^{\text {rd }}$; Ealick, S.E. The structure of human deoxycytidine kinase in complex with clofarabine reveals key interactions for prodrug activation. Acta Crystallogr. D .Biol. Crystallogr. 2006, 62, 133-139.

77. Parker, W.B.; Shaddix, S.C.; Rose, L.M.; Shewach, D.S.; Hertel, L.W.; Secrist, J.A. $3^{\text {rd }}$; Montgomery, J.A.; Bennett, L.L.Jr. Comparison of the mechanism of cytotoxicity of 2-chloro-9(2-deoxy-2-fluoro-beta-D-arabinofuranosyl)adenine, 2-chloro-9-(2-deoxy-2-fluoro-beta-Dribofuranosyl)adenine, and 2-chloro-9-(2-deoxy-2,2-difluoro-beta-D-ribofuranosyl)adenine in CEM cells. Mol. Pharmacol. 1999, 55, 515-520.

78. Gandhi, V.; Kantarjian, H.; Faderl, S.; Bonate, P.; Du, M.; Ayres, M.; Rios, M.B.; Keating, M.J.; Plunkett, W. Pharmacokinetics and pharmacodynamics of plasma clofarabine and cellular clofarabine triphosphate in patients with acute leukemias. Clin. Cancer Res. 2003, 9, 6335-6342.

79. Xie, K.C.; Plunkett, W. Deoxynucleotide pool depletion and sustained inhibition of ribunucleotide reductase and DNA synthesis after treatment of human lymphoblastoid cells with 2-chloro-9-(2deoxy-2-fluoro-beta-D-arabinofuranosyl) adenine. Cancer Res. 1996, 56, 3030-3037.

80. Genini, D.; Adachi, S.; Chao, Q.; Rose, D.W.; Carrera, C.J.; Cottam, H.B.; Carson, D.A.; Leoni, L.M. Deoxyadenosine analogs induce programmed cell death in chronic lymphocytic leukemia cells by damaging the DNA and by directly affecting the mitochondria. Blood 2000, 96, 35373543 .

81. Jeha, S.; Gandhi, V.; Chan, K.W.; McDonald, L.; Ramirez, I.; Madden, R.; Rytting, M.; Brandt, M.; Keating, M.; Plunkett, W.; Kantarjian, H. Clofarabine, a novel nucleoside analog, is active in pediatric patients with advanced leukemia. Blood 2004, 103, 784-789. 
82. Kantarjian, H.; Gandhi, V.; Cortes, J.; Verstovsek, S.; Du, M.; Garcia-Manero, G.; Giles, F.; Faderl, S.; O'Brien, S.; Jeha, S.; Davis, J.; Shaked, Z.; Craig, A.; Keating, M.; Plunkett, W.; Freireich, E.J. Phase 2 clinical and pharmacologic study of clofarabine in patients with refractory or relapsed acute leukemia. Blood 2003, 102, 2379-2386.

83. Kantarjian, H.M.; Gandhi, V.; Kozuch, P.; Faderl, S.; Giles, F.; Cortes, J.; O'Brien, S.; Ibrahim, N.; Khuri, F.; Du, M.; Rios, M.B.; Jeha, S.; McLaughlin, P.; Plunkett, W.; Keating, M. Phase I clinical and pharmacology study of clofarabine in patients with solid and hematologic cancers. $J$. Clin. Oncol. 2003, 21, 1167-1173.

84. Roecker, A.M.; Allison, J.C.; Kisor, D.F. Nelarabine: efficacy in the treatment of clinical malignancies. Future Oncol. 2006, 2, 441-448.

85. Prus, K.L.; Averett, D.R.; Zimmerman, T.P. Transport and metabolism of 9-beta-Darabinofuranosylguanine in a human T-lymphoblastoid cell line nitrobenzylthioinosine-sensitive and -insensitive influx. Cancer Res. 1990, 50, 1817-1821.

86. Rodriguez, C.O.J.; Mitchell, B.S.; Ayres, M.; Eriksson, S.; Gandhi, V. Arabinosylguanine is phosphorylated by both cytoplasmic deoxycytidine kinase and mitochondrial deoxyguanosine kinase. Cancer Res. 2002, 62, 3100-3105.

87. Rodriguez, C.O.Jr.; Stellrecht, C.M.; Gandhi, V. Mechanisms for T-cell selective cytotoxicity of arabinosylguanine. Blood 2003, 102, 1842-1848.

88. Kline, J.P.; Larson, R. Clofarabine in the treatment of acute myeloid leukemia and acute lymphoblastic leukemia: a review. Expert Opin. Pharmacother. 2005, 6, 1-8.

89. Ghandi, V.; Plunkett, W. Clofarabine and nelarabine: two new purine nucleoside analogs. Curr. Opini. Oncol. 2006, 18, 584-590.

90. Beesley, A.H.; Palmer, M.L.; Ford ,J.; Weller, R.E.; Cummings, A.J.; Freitas, J.R.; Firth, M.J.; Perera, K.U.; de Klerk, N,H,.; Kees, U.R. In vitro cytotoxicity of nelarabine, clofarabine and flavopiridol in paediatric acute lymphoblastic leukaemia. Br. J. Haematol. 2007,137, 109-116.

91. Kisor, D.F.; Plunkett, W.; Kurtzberg, J.; Mitchell, B.; Hodge, J.P.; Ernst, T.; Keating, M.J.; Gandhi, V. Pharmacokinetics of nelarabine and 9-beta-D-arabinofuranosyl guanine in pediatric and adult patients during a phase I study of nelarabine for the treatment of refractory hematologic malignancies. J. Clin. Oncol. 2000, 18, 995-1003.

92. Gandhi, V.; Plunkett, W.; Rodriguez, C.O.Jr.; Nowak, B.J.; Du, M.; Ayres, M.; Kisor, D.F.; Mitchell, B.S.; Kurtzberg, J.; Keating, M.J. Compound GW506U78 in refractory hematologic malignancies: relationship between cellular pharmacokinetics and clinical response. J. Clin. Oncol. 1998, 16, 3607-3615.

93. Evans, G.B.; Furneaux, R.H.; Lewandowicz, A.; Schramm, V.L.; Tyler, P.C. Synthesis of secondgeneration transition state analogues of human purine nucleoside phosphorylase. J. Med. Chem. 2003, 46, 5271-5276.

94. Clinch, K.; Evans, G.B.; Fleet, G.W.; Furneaux, R.H.; Johnson, S.W.; Lenz, D.H.; Mee, S.P.; Rands, P.R.; Schramm, V.L.; Taylor Ringia, E.A.; Tyler, P.C. Synthesis and bio-activities of Lenantiomers of two potent transition state analogue inhibitor of purine nucleoside phosphorylases. Org. Biomol. Chem. 2006, 4, 1131-1139. 
95. Canduri, F.; Silva, R.G.; dos Santos, D.M.; Palma, M.S.; Basso, L.A.; Santos, D.S.; de Azevedo, W.F.Jr. Structure of human PNP complexed with ligands. Acta Crystallogr D. Biol. Crystallogr. 2005, 61, 856-862.

96. Bantia, S.; Miller, P.J.; Parker, C.D.; Ananth, S.L.; Horn, L.H.; Kilpatrick, J.M.; Morris, P.E.; Hutchison, T.L.; Montgomery, J.A.; Sandhu, J.S. Purine nucleoside phosphorylase inhibitor BCX1777 (Immucillin-H)- a novel potent and orally active immunosuppressive agent. Intern. Immunopharmacol. 2001, 1,1199-1210.

97. Kicska, G.A.; Long, L.; Horig, H.; Fatrchild, C.; Tyler, P.C.; Furneaux, R.H.; Schramm, V.L.; Kaufman, H.L. Immucillin H, a powerful transition-state analog inhibitor of purine nucleoside phosphorylase, selectively inhibits human T lymphocytes. PNAS 2001, 98, 4593-4598.

98. Banthia, S.; Kilpatrick, J.M. Purine nucleoside phosphorylase inhibitors in T-cell malignancies. Curr. Oppinion Drug Discov. Develop. 2004, 7, 243-247.

99. Ashcroft, M.; Kubbutat, M.H.; Vousden, K.H. Regulation of p53 function and stability by phosphorylation. Mol.Cell Biol. 1999, 19, 1751-1758.

100. Kilpatrick, J.M.; Morris, P.E.; Serota, D.G.jr.; Phillips, D.; Moore, D.R.; Bennett, J.C.; Babu, Y.S. Intravenous and oral pharmacokinetic study of BCX-1777, a novel purine nucleoside phosphorylase transition-state inhibitor. In vivo effects on blood 2'-deoxyguanosine in primates. Int. Immunopharmacol. 2003, 3, 541-548.

101. Piro, L.D.; Miller, W.E.; Carrera, C.J.; Carson, D.A.; Beutler, E. Hairy cell leukemia. N. Engl. J. Med. 1987, 317, 901-902 (letter).

102. Cheson, B.D.; Sorensen, J.M.; Vena, D.A. Treatment of hairy cell leukemia with 2chlorodeoxyadenosine via the Group C Protocol mechanism of the National Cancer Institute: a report of 979 patients. J. Clin. Oncol. 1998, 16, 3007-3015.

103. Juliusson, G.; Lenkei, R.; Liliemark, J. Flow cytometry of blood and bone marrow cells from patients with hairy cell leukemia: phenotype of hairy cell and lymphocyte subsets after treatment with 2-chlorodeoxyadenosie. Blood 1994, 83, 3672-3681.

104. von Rohr, A.; Schmitz, S.F.; Tichelli, A.; Hess, U.; Piguet, D.; Wernli, M.; Frickhofen, N.; Konwalinka, G.; Zulian, G.; Ghielmini, M.; Rufener, B.; Racine, C.; Fey, M.F.; Cerny, T.; Betticher, D.; Tobler, A. Swiss Group for Clinical Cancer Research (SAKK), Bern, Switzerland. Treatment of hairy cell leukemia with cladribine (2-chlorodeoxyadenosine) by subcutaneous bolus injection: a phase II study. Ann. Oncol. 2002, 13, 1641-1649.

105. Tallman, M.S.; Zakarija, A. Hairy cell leukemia survival and relapse: Long-term follow-up of purine analogs-based therapy and approach for relapsed disease. Transfus Apheresis Sci. 2005, 32, 90-103.

106. Saven, A.; Burian, C.; Kozioł, J.A.; Piro, L.D. Long-term follow-up of patients with hairy cell leukemia after cladribine treatment. Blood 1998, 92, 1918-1926.

107. Bastie, J.N.; Cazals-Hatem, D.; Daniel, M.T.; D'Agay, M.F.; Rabian, C.; Glaisner, S.; NoelWalter, M.P.; Dabout, D.; Flandrin, G.; Dombret, H.; Poisson, D.; Degos, L.; Castaigne, S. Five years follow-up after 2-chlorodeoxyadenosine treatment in thirty patients with hairy cell leukemia: evaluation of minimal residual disease and CD4+ lymphocytopenia after treatment. Leuk. Lymphoma 1999, 35, 555-565. 
108.Zinzani, P.L.; Tani, M.; Marchi, E.; Stefoni, V.; Alinari, L.; Musuraca, G.; Gabriele, A.; Pileri, S.; Baccarani, M. Long-term follow-up of front line treatment of hairy cell leukemia with 2chlorodeoxyadenosine. Haematol. 2004, 89, 309-313.

109. Goodman, G.R.; Burian, C.; Koziol, J.A.; Saven, A. Extended follow-up of patients with hairy cell leukemia after treatment with cladribine. J. Clin. Oncol. 2003, 21, 891-896.

110. Hoffman, M.A.; Janson, D., Rose, E.; Rai, K.R. Treatment of hairy cell leukemia with cladribine: response, toxicity and long-term follow-up. J. Clin. Oncol. 1997, 15, 1138-1142.

111. Robak, T.; Błasińska-Morawiec, M.; Błoński, J.; Hellmann, A.; Hałaburda, K.; Konopka, L.; Kotlarek-Haus, S.; Potoczek, S.; Hansz, J.; Dmoszyńska, A.; Urasiński, I.; Zdziarska, B.; Dwilewicz-Trojaczek, J.; Hołowiecki, J.; Skotnicki, A.B. 2-chlorodeoxyadenosine: (cladribine) in the treatment of hairy cell leukemia and hairy cell leukemia variant 7-year experience in Poland. Eur. J. Haematol. 1999, 62, 49-56.

112. Lauria, F.; Boachia, M.; Marotta, G.; Respadori, D.; Zinzani, P.L., Rondelli, D. Weekly administration of 2-chlorodeoxyadenosine in patients with hairy cell leukemia is effective and reduces infectious complications. Haematol. 1999, 84, 22-25.

113. Robak, T.; Jamroziak, K.; Gora-Tybor, J.; Blonski, J.Z.; Kasznicki, M.; Dwilewicz-Trojaczek, J.; Wiater, E.; Zdunczyk, A.; Dybowicz, J.; Dmoszynska, A.; Wojtaszko, M.; Zdziarska, B.; Calbecka, M.; Kostyra, A.; Hellmann, A.; Lewandowski, K.; Stella-Holowiecka, B.; Sulek, K.; Gawronski, K.; Skotnicki, A.B.; Nowak, W.; Zawilska, K.; Molendowicz-Portala, L.; Kloczko, J.; Sokolowski, J.; Warzocha, K.; Seferynska, I.; Ceglarek, B.; Konopka, L. Cladribine in a weekly versus daily schedule for untreated active hairy cell leukemia: final report from the Polish Adult Leukemia Group (PALG) of a prospective randomized, multicenter trial. Blood 2007,109, 36723675 .

114. Liliemark, J.; Albertioni, F.; Hassan, M.; Juliusson, G. On the bioavailability of oral and subcutaneous 2-chloro-2-deoxyadenosine in humans: alternative routes of administration. J. Clin. Oncol. 1992, 10, 1514-1518.

115. Juliusson, G.; Heldal, D.; Hippe, E.; Hedenus, M.; Malm, C.; Wallman, K.; Stolt, C.M.; Evensen, S.A.; Albertioni, F.; Tjønnfjord, G. et al. Subcutaneous injections of 2-chlorodeoxyadenosine for symptomatic hairy cell leukemia. J. Clin. Oncol. 1995, 13, 989-995.

116. Spiers, A.S.; Parekh, S.J.; Bishop, M.B. Hairy cell leukemia: induction of complete remission with pentostatin (2'-deoxycoformycin). J. Clin. Oncol. 1984, 2,1336-1342.

117. Spiers, A.S.; Moore, D.; Cassileth, P.A.; Harrington, D.P.; Cummings, F.J.; Neiman, R.S.; Bennett, J.M;. O'Connell, M.J. Remissions in hairy cell leukemia with pentostatin (2'deoxycoformycin). N. Engl. J. Med. 1987, 316, 825-830.

118. Kraut, E.H.; Bouroncle, B.A.; Grever, M.R. Pentostatin in the treatment of advanced hairy cell leukemia. J. Clin. Oncol. 1989, 7, 168-172.

119. Grever, M.R.; Doan, C.A.; Kraut, E.H. Pentostatin in the treatment of hairy cell leukemia. Best Pract. Res. Clin. Haematol. 2003, 16, 91-99.

120. Thaler, J.; Grünewald, K.; Gattringer, C.; Ho, A.D.; Weyrer, K.; Dietze, O.; Stauder, R.; Fluckinger, T.; Lang, A.; Huber, H. Long-term follow-up of patients with hairy cel leukaemia treated with pentostatin: lymphocyte subpopulations and residual bone marrow infiltration. Br. J. Haematol. 1993, 84, 75-82. 
121. Dearden, C.R.; Matutes, E.; Hilditch, B.T.; Wansbury, G.J.; Catovsky, D. Long term follow-up patients with hairy cell leukemia after treatment with pentostatin or cladribine. Br. J. Haematol. 1999, 106, 515-519.

122. Ribeiro, P.; Bouaffia, F.; Peaud, P.Y.; Blanc, M.; Salles, B.; Salles, G.; Coiffier, B. Long-term outcome of patients with hairy cell leukemia treated with pentostatin. Cancer 1999, 85, 65-71.

123. Rafel, M.; Cervantes, F.; Beltrán, J.M.; Zuazu, F.; Hernández Nieto, L.; Rayón, C.; García Talavera, J.; Montserrat, E. Deoxycoformycin in the treatment of patients with hairy cell leukemia: results of a Spanish collaborative study of 80 patients. Cancer 2000, 88, 352-357.

124. Johnston, J.B.; Eisenhauer, E.; Wainman, N.; Corbett, W.E.; Zaentz, S.D.; Daeninck, P.J. Longterm outcome following treatment of hairy cell leukemia with pentostatin (Nipent): a National Cancer Institute of Canada study. Semin. Oncol. 2000, 27, 32-36.

125. Habermann, T.M.; Andersen, J.W.; Cassileth, P.A.; Bennett, J.M.; Oken, M.M. Sequential administration of recombinant interferon alpha and deoxycoformycin in the treatment of hairy cell leukaemia. Br. J. Haematol. 1992, 80, 466-471.

126. Flinn, I.W.; Kopecky, K.J.; Foucar, M.K.; Head, D.; Bennett, J.M.; Hutchison, R., Corbett, W.; Cassileth, P.; Habermann, T.; Golomb, H.; Rai, K.; Eisenhauer, E.; Appelbaum, F.; Cheson, B.; Grever, M.R. Long-term follow-up of remission duration, mortality and second malignancies in hairy cell leukemia patients treated with pentostatin. Blood 2000, 96, 2981-2986.

127. Maloisel, F.; Benboubker, L.; Gardembas, M.; Coiffier, B.; Divine, M.; Sebban, C.; Blanc, M.; Abgrall, J.F.; Lederlin, P.; Harousseau, J.L.; Blaise, A.M.; Grosbois, B.; Morice, P.; Ghandour, C.; Castaigne, S. Long-term outcome with pentostatin treatment in hairy cell leukemia patients. A French retrospective study of 238 patients. Leukemia 2003, 17, 45-51.

128. Grever, M.; Kopecky, K.; Foucar, M.K.; Head, D.; Bennett, J.M.; Hutchison, R.E.; Corbett, W.E.; Cassileth, P.A.; Habermann, T.; Golomb, H. et al. Randomized comparison of pentostatin versus interferon alfa-2a in previously untreated patients with hairy cell leukemia: an Intergroup study. $J$. Clin. Oncol. 1995, 13, 974-982.

129. Else, M.; Ruchlemer, R.; Osuji, N.; Del Giudice, I.; Matutes, E.; Woodman, A.; Wotherspoon, A.; Swansbury, J.; Dearden, C.; Catovsky, D. Long remissions in hairy cell leukemia with purine analogs. A report of 219 patients with a median follow-up of 12.5 years. Cancer 2005, 104, 24422448.

130. Kantarjian, H.; Schachner, J.; Keating, M.J. Fludarabine therapy in hairy cell leukemia. Cancer 1991, 67, 1291-1293.

131. Rai, K.R.; Peterson, B.L.; Appelbaum, F.R.; Kolitz, J.; Elias, L.; Shepherd, L.; Hines, J.; Threatte, G.A.; Larson, R.A.; Cheson, B.D.; Schiffer, C.A. Fludarabine compared with chlorambucil as primary therapy for chronic lymphocytic leukemia. N. Engl. J. Med. 2000, 343, 1760-1767.

132. Robak, T.; Bloński, J.Z.; Kasznicki, M.; Blasińska-Morawiec, M.; Krykowski, E.; Dmoszyńska, A.; Mrugala-Spiewak, H.; Skotnicki, A.B.; Nowak, W.; Konopka, L.; Ceglarek, B.; Maj, S.; Dwilewicz-Trojaczek, J.; Hellmann, A.; Urasiński, I.; Zdziarska, B.; Kotlarek-Haus, S.; Potoczek, S.; Grieb, P. Cladribine with prednisone versus chlorambucil with prednisone as first-line therapy in chronic lymphocytic leukemia: report of a prospective, randomized, multicenter trial. Blood 2000, 96, 2723-2729. 
133. Robak, T.; Błoński, J.Z.; Kasznicki, M.; Góra-Tybor, J.; Dmoszyńska, A.; Wojtaszko, M.; Skotnicki, A.B.; Nowak, W.; Hellmann, A.; Lewandowski, K.; Zdziarska, B.; Konopka, L.; Ceglarek, B.; Dwilewicz-Trojaczek, J.; Boguradzki, P.; Kuliczkowski, K.; Sułek, K.; Warzocha, $\mathrm{K}$. Comparison of cladribine plus prednisone with chlorambucil plus prednisone in patients with chronic lymphocytic leukemia. Final report of the Polish Adult Leukemia. Final report of the Polish Adult Leukemia Group (PALG CLL1). Med. Sci. Monit. 2005, 11, 171-180.

134. Johnson, S.; Smith, A.G.; Löffler, H.; Osby, E.; Juliusson, G.; Emmerich, B.; Wyld, P.J.; Hiddemann, W.; The French Cooperative Group on CLL. Multicentre prospective randomised trial of fludarabine versus cyclophosphamide, doxorubicin and prednisone (CAP) for treatment of advanced stage chronic lymphocytic leukemia. Lancet 1996, 347, 1432-1438.

135. Leporrier, M.; Chevret, S.; Cazin, B.; Boudjerra, N.; Feugier, P.; Desablens, B.; Rapp, M.J.; Jaubert, J.; Autrand, C.; Divine, M.; Dreyfus, B.; Maloum, K.; Travade, P.; Dighiero, G. Binet, J.L.; Chastang, C.; The French Cooperative Group on Chronic Lymphocytic Leukemia. Randomized comparison of fludarabine, CAP, and CHOP in 938 previously untreated stage B and C chronic lymphocytic leukemia patients. Blood 2001, 98, 2319-2325.

136. Keating, M.J.; O'Brien, S.; Kantarjian, H.; Plunkett, W.; Estey, E.; Koller, C.; Beran, M.; Freireich, E.J. Long-term follow-up of patients with chronic lymphocytic leukemia treated with fludarabine as a single agent. Blood 1993, 81, 2878-2884.

137. Steurer, M.; Pall, G.; Richards, S.; Bohlius, J.; Greil, R. Cochrane Haematologic Malignancies Group. Single agent purine analogues for the treatment of chronic lymphocytic leukemia: a systematic review and meta- analysis. Cancer Treat. Rev. 2006, 32, 377-389.

138. Robak, T.; Bloński, J.Z.; Kasznicki, M.; Konopka, L.; Ceglarek, B.; Dmoszyńska, A.; SorokaWojtaszko, M.; Skotnicki, A.B.; Nowak, W.; Dwilewicz-Trojaczek, J.; Tomaszewska, A.; Hellmann, A.; Lewandowski, K.; Kuliczkowski, K.; Potoczek, S.; Zdziarska, B.; Hansz, J.; Kroll, R.; Komarnicki, M.; Holowiecki, J.; Grieb, P. Cladribine with or without prednisone in the treatment of previously treated and untreated B-cell chronic lymphocytic leukemia- updated results of the multicentre study of 378 patients. Br. J. Haematol. 2000, 108, 357-368.

139. Keating, M.J.; O'Brien, S.; Lerner, S.; Koller, C.; Beran, M.; Robertson, L.E.; Freireich, E.J.; Estey, E.; Kantarjian, H. Long term follow-up of patients with chronic lymphocytic leukemia (CLL) receiving fludarabine regiments as initial therapy. Blood 1998, 92, 1165-1171.

140. Piro, L.D.; Carrera, C.J.; Beutler, E.; Carson, D.A. 2-Chlorodeoxyadenosine: an effective new agent for the treatment of chronic lymphocytic leukemia. Blood 1988, 71, 1069-1073.

141. Dillman, R.O. Pentostatin (Nipent) in the treatment of chronic lymphocyte leukemia and hairy cell leukemia. Expert Rev. Anticancer Ther. 2004, 4, 27-36.

142. Boogaerts, M.A. Oral fludarabine therapy in chronic lymphocytic leukemia-increased convenience. Hematology 2004, 5, 31-37.

143. O'Brien, S.M.; Kantarjian, H.M.; Cortes, J.; Beran, M.; Koller, C.A.; Giles, F.J.; Lerner, S.; Keating, M. Results of the fludarabine and cyclophosphamide combination regimen in chronic lymphocytic leukemia. J. Clin. Oncol. 2001, 19, 1414-1420.

144. Hallek, M.; Schmitt, B.; Wilhelm, M.; Busch, R.; Kröber, A.; Fostitsch, H.P.; Sezer, O.; Herold, M.; Knauf, W.; Wendtner, C.M.; Kuse, R.; Freund, M.; Franke, A.; Schriever, F.; Nerl, C.; Döhner, H.; Thiel, E.; Hiddemann, W.; Brittinger, G.; Emmerich, B.; German Chronic 
Lymphocytic Leukaemia Study Group. Fludarabine plus cyclophosphamide is an efficient treatment for advanced chronic lymphocytic leukaemia (CLL): results of a phase II study of the German CLL Study Group. Br. J. Haematol. 2001,14, 342-348.

145.Eichhorst, B.F.; Busch, R.; Hopfinger, G.; Pasold ,R.; Hensel, M.; Steinbrecher, C.; Siehl, S.; Jäger, U.; Bergmann, M.; Stilgenbauer, S.; Schweighofer, C.; Wendtner, C.M,; Döhner, H.; Brittinger, G.; Emmerich, B.; Hallek, M.; German CLL Study Group. Fludarabine plus cyclophosphamide versus fludarabine alone in first-line therapy of younger patients with chronic lymphocytic leukemia. Blood 2006, 107, 885-891.

146. Flinn, I.W.; Neuberg, D.S.; Grever, M.R.; Dewald, G.W.; Bennett, J.M.; Paietta, E.M.; Hussein, M.A.; Appelbaum, F.R.; Larson, R.A.; Moore, D.F.Jr.; Tallman, M,S. Phase III trial of fludarabine plus cyclophosphamide compared with fludarabine for patients with previously untreated chronic lymphocytic leukemia: US Intergroup Trial E2997. J. Clin. Oncol. 2007, 25, 793-798.

147. Catovsky, D.; Richards, S.; Matutes, E.; Oscier, D.; Dyer, M.J.; Bezares, R.F.; Pettitt, A.R,; Hamblin, T.; Milligan, D.W.; Child, J.A.; Hamilton, M.S.; Dearden, C,E.; Smith, A.G.; Bosanquet, A.G.; Davis, Z.; Brito-Babapulle, V.; Else, M.; Wade, R.; Hillmen, P; UK National Cancer Research Institute (NCRI) Haematological Oncology Clinical Studies Group; NCRI Chronic Lymphocytic Leukaemia Working Group. Assessment of fludarabine plus cyclophosphamide for patients with chronic lymphocytic leukemia (the LRF CLL4 Trial): a randomized controlled trial. Lancet 2007, 370, 230-239.

148. Montillo, M.; Tedeschi, A.; O'Brien, S.; Di Raimondo, F.; Lerner, S.; Ferrajoli, A.; Morra, E.; Keating, M.J. Phase II study of cladribine and cyclophosphamide in patients with chronic lymphocytic leukemia and prolymphocytic leukemia. Cancer 2003, 97, 114-120.

149. Robak, T.; Błoński, J.Z.; Kasznicki, M.; Góra-Tybor, J.; Dwilewicz-Trojaczek, J.; StellaHołowiecka, B.; Wołowiec, D. Cladribine combined with cyclophosphamide is highly effective in the treatment of chronic lymphocytic leukemia. Hematol. J. 2002, 3, 244-250.

150. Robak, T., Blonski, J.Z.; Jamroziak, K.; Gora-Tybor, J.; Stella-Holowiecka, B.; Konopka, L.; Ceglarek, B.; Warzocha, K.; Seferynska, I.; Kloczko, J.; Piszcz, J.; Calbecka, M.; Kostyra, A.; Dwilewicz-Trojaczek, J.; Wiater, E.; Dmoszynska, A.; Kowal, M.; Zawilska, K.; Grzywacz, A.; Hellmann, A.; Mital, A.; Zduńczyk, A.; Dębowicz, J.; Kuliczkowski, K.; Potoczek, S.; Skotnicki, A.; Nowakowska-Domagala, M.; Lewandowski, K.; Sulek, K. Randomized comparison of cladribine plus cyclophosphamide with fludarabine plus cyclophosphamde in untreated patients with chronic lymphocytic leukemia: Report of the Polish Adult Leukemia Group (PALG-CLL3). Blood 2008, 112, 732a (Abstract 2103).

151. Weiss, M.A.; Maslak, P.G.; Jurcic, J.G.; Scheinberg, D.A.; Aliff, T.B.; Lamanna N.; Frankel S.R.; Kossman, S.E.; Horgan, D. Pentostatin and cyclophosphamide: an effective new regimen in previously treated patients with chronic lymphocytic leukemia. J. Clin. Oncol. 2003, 21, 12781284.

152. Tsimberidou, A.M.; Keating, M.J.; Giles, F.J.; Wierda, W.G.; Ferrajoli, A.; Lerner, S.; Beran, M.; Andreeff, M.; Kantarjian, H.M.; O'Brien, S. Fludarabine and mitoxantrone for patients with chronic lymphocytic leukemia. Cancer 2004, 100, 2583-2591. 
153. Bosch, F.; Ferrer, A.; López-Guillermo, A.; Giné, E.; Bellosillo, B.; Villamor, N.; Colomer, D.; Cobo, F.; Perales, M.; Esteve, J.; Altés, A.; Besalduch, J.; Ribera, J.M.; Montserrat, E. For the GELCAB (Grup per l'Estudi dels Limfomes a Catalunya i Balears). Fludarabine, cyclophosphamide and mitoxantrone in the treatment of resistant or relapsed chronic lymphocytic leukemia. Br. J. Haematol. 2002, 119, 976-984.

154. Robak, T.; Góra-Tybor, J.; Lech-Marańda, E.; Błoński, J.Z.; Kasznicki, M. Cladribine in combination with mitoxantrone and cyclophosphamide (CMC) in the treatment of heavily pretreated patients with advanced indolent lymphoid malignancies. Eur. J. Haematol. 2001, 66, 188194.

155. Robak, T.; Błoński, J.Z.; Kasznicki, M.; Góra - Tybor, J.; Dwilewicz-Trojaczek, J.; Boguradzki, P.; Konopka, L.; Ceglarek, B.; Sułek, J.; Kuliczkowski, K.; Wołowiec D, Stella-Hołowiecka B, Skotnicki AB, Nowak W, Moskwa-Sroka B, Dmoszyńska, A.; Calbecka, M. Cladribine combined with cyclophosphamide and mitoxantrone as front-line therapy in chronic lymphocytic leukemia. Leukemia 2001, 15, 1510-1516.

156. Robak, T.; Blonski, J.Z.; Gora-Tybor, J.; Jamroziak, K.; Dwilewicz-Trojaczek, J.; Tomaszewska, A.; Konopka, L.; Ceglarek, B.; Dmoszynska, A.; Kowal, M.; Kloczko, J.;Stella-Holowiecka, B.; Sulek, K.; Calbecka, M.; Zawilska, K.; Kuliczkowski, K.; Skotnicki,A.B.; Warzocha, K.; Kasznicki, M. Polish Leukemia Group (PALG CLL2).Cladribine alone and in combination with cyclophosphamide or cyclophosphamide plus mitoxantrone in the treatment of progressive chronic lymphocytic leukemia: report of a prospective, multicenter, randomized trial of the Polish Adult Leukemia Group (PALG CLL2). Blood. 2006, 108, 473-479.

157. Robak, T. Novel monoclonal antibodies for chronic lymphocytic leukemia. Curr. Cancer Drug Targets 2008, 8, 156-171.

158. Keating, M.J.; O'Brien, S.; Albitar, M.; Lerner, S.; Plunkett, W.; Giles, F.; Andreeff, M.; Cortes, J.; Faderl, S.; Thomas, D.; Koller, C.; Wierda, W.; Detry, M.A.; Lynn, A.; Kantarjian, H. Early results of a chemoimmunotherapy regimen of fludarabine, cyclophosphamide and rituximab as initial therapy for chronic lymphocytic leukemia. J. Clin. Oncol. 2005, 23, 4079-4088.

159. Wierda, W.; O'Brien, S.; Wen, S.; Faderl, S.; Garcia-Manero, G.; Thomas, D.; Do, K.A.; Cortes, J.; Koller, C.; Beran, M.; Ferrajoli, A.; Giles, F.; Lerner, S.; Albitar, M.; Kantarjian, H.; Keating, M. Chemoimmunotherapy with fludarabine, cyclophosphamide and rituximab for relapsed and refractory chronic lymphocytic leukemia. J. Clin. Oncol. 2005, 23, 4070-4078.

160. Byrd, J.C.; Rai, K.; Peterson, B.L.; Appelbaum, F.R.; Morrison, V.A.; Kolitz, J.E.; Shepherd, L.; Hines, J.D.; Schiffer, C.A.; Larson, R.A. Addition of rituximab to fludarabine may prolong progression-free survival and overall survival in patients with previously untreated chronic lymphocytic leukemia: an updated retrospective analysis of CALGB 9712 and CALGB 9011. Blood 2005,105, 49-53.

161. Hallek, M.; Fingerle-Rowson, G.; Fink, A.M.; Busch, R.; Mayer, J.; Hensel, M.; Hopfinger, G.; Hess, G.; von Gruenhagen, U.; Bergmann, M.A.; Catalano, J.; Zinzani, P.L.; Caligaris Cappio, F.; Seymour, F.J.; Berrebi, A.; Jaeger, U.; Cazin, B.; Trneny, M.; Westermann, A.; Wendtner, C. MD ${ }^{1}$; Eichhorst, B.F.; Staib, P.; Boettcher, S.; Ritgen, M.; Stilgenbauer, S.; Mendila, M.; Kneba, M.; Döhner, H.; Fischer, K. Immunochemotherapy with fludarabine (F), cyclophosphamide (C), and rituximab (R) (FCR) versus fludarabine and cyclophosphamide (FC) improves response rates 
and progression-free survival (PFS) of previously untreated patients (pts) with advanced chronic lymphocytic leukemia (CLL). Blood 2008, 112, 125a (Abstract 325).

162. Robak, T. ; Moiseev, S.; Dmoszynska, A.; Solal-Céligny, P.; Warzocha, K.; Javier Loscertales, J.; Catalano, J. MD.; Afanasiev, B.V.; Larratt, L.; Geisler, C.; Montillo, M.; Ganly, P.; Dartigeas, C.; Rosta, A.; Janssens, A.; Mendila, M.; Maurer, J.; Wenger, M.K. Rituximab, fudarabine, and cclophosphamide (R-FC) polongs pogression fee survival in relapsed or refractory chronic lymphocytic leukemia (CLL) cmpared with FC aone: Final results from the international randomized phase III REACH tial. Blood 2008, 112, LBA-1(Abstract 157420).

163. Robak, T.; Smolewski, P.; Cebula, B.; Grzybowska-Izydorczyk, O.; Błoński, J.Z. Rituximab plus cladribine with or without cyclophosphamide in patients with relapsed or refractory chronic lymphocytic leukemia. Eur. J. Haematol. 2007, 79, 107-113.

164. Robak, T.; Smolewski, P.; Cebula, B.; Szmigielska-Kaplon, A.; Chojnowski, K.; Blonski, J.Z.; Rituximab combined with cladribine or with cladribine and cyclophosphamide in heavily pretreated patients with indolent lymphoproliferative disorders and mantle cell lymphoma. Cancer 2006,107, 1542-1550.

165. Absi, A.; Hsi, E.; Kulaycio, M. Prolymphocytic leukemia. Curr. Treat Options Oncol. 2005, 6, 197-208.

166. Robak, T.; Robak, P. Current treatment options in prolymphocytic leukemia. Med. Sci. Monit. 2007, 13, RA 69-80.

167. Krishnan, B.; Matutes, E.; Dearden, C. Prolymphocytic leukemias. Semin Oncol. 2006, 33, $257-$ 263.

168. Palomera, L.; Domingo, J.M.; Agullo, J.A.; Romero, M. Complete remission in T-cell prolymphocytic leukemia with 2-chlorodeoxyadenosine (Letter). J.Clin. Oncol. 1995, 13, 12841285.

169. Saven A, Lee T, Schlutz M, Jacobs A, Ellison D, Longmire R, Piro L. Major activity of cladribine in patients with de novo B-cell prolymphocytic leukemia. J. Clin. Oncol. 1997, 15, 37-43.

170. Mercieca, J.; Matutes, E.; Dearden, C.; MacLennan, K.; Catovsky, D. The role of pentostatin in the treatment of T-cell malignancies: analysis of response rate in 145 patients according to disease subtype. J. Clin. Oncol. 1994,12, 2588-2593.

171. Kantarjian, H.M.; Childs, C.; O'Brien, S.; Huh, Y.; Beran, M.; Schachner, J.; Koller, C.; Keating, M.J. Efficacy of fludarabine, a new adenine nucleoside analogue, in patients with prolymphocytic leukemia and the prolymphocytoid variant of chronic lymphocytic leukemia. Am. J. Med. 1991, 90, 223-228.

172. Dohner, H.; Ho, A.D.; Thaler, J.; Stryckmans, P.; Sonneveld, P.; de Witte, T.; Lechner, K.; Lauria, F, Bodewadt-Radzun, S.; Suciu, S. Pentostatin in prolymphocytic leukemia: phase II trial of the European Organization for Research and Treatment of Cancer Leukemia Cooperative Study Group. J. Natl. Cancer Inst. 1993, 85, 658-662.

173. Doorduijn, J.K.; Michiels, J.J. Effectiveness of fludarabine in end-stage prolymphocytic leukemia. Leukemia 1994, 8, 1439.

174. Jeha, S.; Razzouk, B.; Rytting, M.E.; Gaynon, P.S.; Kadota, R.; Rheingold, S.; Luchtman-Jones, L.; Shen, V.; Arceci, R.J.; Fernandez, M.; Weitman, S.; Steinherz, P.G. Phase II trials of clofarabine in relapsed or refractory pediatric leukemia.Blood 2004, 104,196a (Abstract 684). 
175. Jeha, S.; Gaynon, P.S.; Steinherz, P.;Kadota, R.; Bomgaars, L.; Razzouk,B.; Luchtman-Jones, L.; Altman, A.; Rheingold, S.; Ritchey, A.K.; Shen, V.; Weiss, J.; Chan, K.W.; Craig, A.; Arceci, R.J. A Phase II, open-label study of clofarabine in pediatric patients with refractory or relapsed acute lymphoblastic leukemia. Blood 2003, 102, 881a (Abstract 3277).

176. Jeha, S.; Steinherz, P.; Gaynon, P.S.;Rheingold, S.;Razzouk, B.; Ritchey, A.K.;Altman, A.; Albano, E.; Stine, K.; Chan, K.W.; Weiss, J.; Craig, A.;Arceci, R.J. A Phase II, open-label study of clofarabine in pediatric patients with refractory or relapsed acute myelogenous leukemia. Blood 2003, 102, 617a (Abstract 2278).

177. Jeha, S.; Gaynon, P.S.; Razzouk, B.I.; Franklin, J.; Kadota, R.; Shen, V.; Luchtman-Jones, L.; Rytting, M.; Bomgaars, L.R.; Rheingold, S.; Ritchey, K.; Albano, E.; Arceci, R.J.; Goldman, S.; Griffin, T.; Altman, A.; Gordon, B.; Steinherz, L.; Weitman, S.; Steinherz, P. Phase II study of clofarabine in pediatric patients with refractory or relapsed acute lymphoblastic leukemia. J. Clin. Oncol. 2006, 24, 1917-1923.

178. Gidwani, P.; Ramesh, K.H.; Liu, Y.; Kolb, E.A. The comparison of clofarabine and cytarabine in pediatric relapsed acute lymphoblastic leukemia: a case report. Chemotherapy 2008, 54, 120-124.

179. Karp, J.E.; Ricklis, R.M.; Balakrishnan, K.; Briel, J.; Greer, J.; Gore, S.D.; Smith, B.D.; McDevitt, M.A.; Carraway, H.; Levis, M.J.; Gandhi, V. A phase 1 clinical-laboratory study of clofarabine followed by cyclophosphamide for adults with refractory acute leukemias. Blood 2007, 110, 1762-1769.

180. Cohen, M.H.; Johnson, J.R.; Justice, R.; Pazdur, R.; FDA drug approval summary: nelarabine (Arranon) for the treatment of T-cell lymphoblastic leukemia/lymphoma. Oncologist. 2008, 13, 709-714.

181. Kurtzberg, J.; Ernst, T.J.; Keating, M.J.; Gandhi, V.; Hodge, J.P.; Kisor, D.F.; Lager, J.J.; Stephens, C.; Levin, J.; Krenitsky, T.; Elion, G.; Mitchell, B.S. Phase I study of 506U78 administered on a consecutive 5-day schedule in children and adults with refractory hematologic malignancies. J. Clin. Oncol. 2005, 23, 3396-3403.

182. Berg, S.L.; Blaney, S.M.; Devidas, M.; Lampkin, T.A.; Murgo, A.; Bernstein, M.; Billett, A.; Kurtzberg, J.; Reaman, G.; Gaynon, P.; Whitlock, J.; Krailo, M.; Harris, M.B. Phase II study of nelarabine (compound 506U78) in children and young adults with refractory T-cell malignancies: a report from the Children's Oncology Group. J. Clin. Oncol. 2005, 23, 3376-3403.

183. Furman, R.R.; Iosava, G.; Isola, L.; Ravandi, F.; Zodelava, M.; Bennett, J.C.; Kilpatrick, J.M.; Bantia, S., Forodesine (Fodosine ${ }^{\mathrm{TM}}$ ), a PNP inhibitor active in relapsed or refractory T-cell leukemia patients (Phase II study). Blood 2005, 106, 259a (Abstract 881).

184. Stelljes, M.; Kienast, J.; Berning, B.; Gokbuget, M.; Hoelzer, D.; Silling, G.; Berdel, W.E.; Dahl, G.V.H.; Schissel, D.; Hemenway, M.; Gore, L.Forodesine in patients with refractory/relapsed TALL can induce prolonged stable remission with minimal toxicity before and after allogeneic hematopoietic stem cell transplantation. Blood 2006, 108, 427b (Abstract 5340).

185. Furman, R.R.; Gandhi, V.V.; Bennett, J.C.; Bantia, S.; Kilpatrick, J.M., Intravenous Forodesine (BCX-1777), a novel purine nucleoside phosphorylase (PNP) inhibitor, demonstrates clinical activity in phase I/II studies in patients with B-Cell acute lymphoblastic leukemia. Blood 2004, 104, 750a (Abstract 2743). 
186. Ritchie, E.; Gore, L.; Roboz, G.J.; Feldman, E.; Ravandi, F.; Furman, R. Phase II study of forodesine, a PNP inhibitor, in patients with relapsed or refractory B-lineage acute lymphoblastic leukemia Blood 2006, 108, 533a (Abstract 1881).

187. Tondini, C.; Balzarotti, M.; Rampinelli, J.; Valagussa, P.; Luoni,M.; DePaoli, A.; Santoro, A.; Bonadonna, G. Fludarabine and cladribine in relapsed/refractory low-grade non-Hodgkin's lymphoma: a phase II randomized study. Ann. Oncol. 2000, 11, 231-233.

188. Robak, T.; Góra-Tybor, J.; Krykowski, E.; Walewski, J.A.; Borawska, A.; Pluzanska, A.; Potemski, P.; Hellmann, A.; Zaucha, J.M.; Konopka, L.; Ceglarek, B.; Durzynski, T.; Sikorska, A`; Michalak, K.; Urasinski, J.; Opalinska, J.; Dmoszynska, A.; Adamczyk-Cioch, M.B.; Kuratowska, Z; Dwilewicz-Trojaczek, J.; Boguradzki, P.; Deren, M; Maj, S.; Grieb, P. Activity of 2-chlorodeoxyadenosine (Cladribine) in 2-hour intravenous infusion in 94 previously treated patients with low grade non-Hodgkin's lymphoma. Leuk. Lymphoma. 1997, 26, 99-105.

189. Tulpule, A.; Schiller, G.; Harycy-Buchman, L.; Tulpule, A.; Schiller, G.; Harvey-Buchanan, L.A.; Lee, M.; Espina, B.M.; Khan, A.U.; Boswell, W.; Nathwani, B.; Levine, A.M. Cladribine in the treatment of advanced relapsed or refractory low and intermediate grade non-Hodgkin's lymphoma. Cancer 1998, 83, 2370-2376.

190. Blum, K.A.; Johnson, J.L.; Niedzwiecki, D.; Piro, L.D.; Saven, A.; Peterson, B.A.; Byrd, J.C.; Cheson, B.D. Cancer and Leukemia Group B Study 9153. Prolonged follow-up after initial therapy with 2-chlorodeoxyadenosine in patients with indolent non-Hodgkin lymphoma: results of Cancer and Leukemia Group B Study 9153. Cancer 2006, 107, 2817-2825.

191.Kong, L.R.; Huang, C.F.; Hakimian, D.; Variakojis, D.; Klein, L.; Kuzel, T.M.; Gordon, L.I.; Zanzig, C.; Wollins, E.; Tallman, M.S. Long term follow-up and late complications of 2chlorodeoxyadenosine in previously treated, advanced, indolent non-Hodgkin's lymphoma. Cancer 1998, 82, 957-964.

192. Saven, A.; Emanuele, S.; Kosty, M.; Kozioł, J.; Ellison, D.; Piro, L. 2-Chlorodeoxyadenosine activity in patients with untreated, indolent non-Hodgkin's lymphoma. Blood. 1995, 86, 17101716.

193. Fridrik, M.A.; Jager, G.; Kienzer, H.R.; Hausmaninger, H.; Oppitz, P.; Krieger, O.; Zabernigg, A.; Lang, A.; Neubauer, M.; Weidinger, G.; Schiller, L.; Seewann, H.L.; Chott, A.; Linkesch, W. Efficacy and toxicity of 2-Chlorodeoxyadenosine (Cladribine)--2 $\mathrm{h}$ infusion for 5 days--as firstline treatment for advanced low grade non-Hodgkin's lymphoma. Eu.r J. Cancer 1998, 34, 15601564.

194. Liliemark, J.; Martinsson, U.; Cavallin-Ståhl, E.; Svedmyr, E.; Porwit, A.; Strömberg, M.; Juliusson, G. Cladribine for untreated or early low-grade non-Hodgkin's lymphoma. Leuk. Lymphoma 1998, 30, 573-581.

195. Robak, T.; Góra-Tybor, J.; Urbańska-Ryś, H.; Krykowski, E. Combination regimen of 2chlorodeoxyadenosine (cladribine), mitoxantrone and dexamethasone (CMD) in the treatment of refractory and recurrent low grade non-Hodgkin's lymphoma. Leuk. Lymphoma. 1999, 32, 359363.

196. Van den Neste, E.; Louviaux, I.; Michaux, J.L.; Sonet, A.; Bosly, A.; Doyen, C.; Mineur, P.; Andre, M.; Straetmans, N.; Coche, E.; Venet, C.; Duprez, T.; Ferrant, A. Phase I/II study of 2- 
chloro-2'-deoxyadenosine with cyclophosphamide in patients with pretreated B cell chronic lymphocytic leukemia and indolent non-Hodgkin's lymphoma. Leukemia 2000, 14, 1136-1142.

197. Armitage, J.O.; Tobinai, K.; Hoelzer, D.; Rummel, M.J. Treatment of indolent non-Hodgkin's lymphoma with cladribine as single-agent therapy and in combination with mitoxantrone. Int. J.Hematol. 2004, 79, 311-321.

198. Riccioni, R.; Caracciolo, F.; Galimberti, S.; Cecconi, N.; Petrini, M. Low dose 2-CdA schedule activity in splenic marginal zone lymphomas. Hematol. Oncol. 2003, 21, 163-168.

199.Zinzani, P.L.; Tani, M.; Fanti, S.; Stefoni, V.; Musuraca, G.; Vitolo, U.; Perrotti, A.; Fina, M.; Derenzini, E.; Baccarani, M. A phase 2 trial of fludarabine and mitoxantrone chemotherapy followed by yttrium-90 ibritumomab tiuxetan for patients with previously untreated, indolent, nonfollicular, non-Hodgkin lymphoma. Cancer 2008, 112, 856-862.

200. Rummel, M.J.; Chow, K.U.; Karakas, T.; Jäger, E.; Mezger, J.; von Grünhagen, U.; Schalk, K.P.; Burkhard, O.; Hansmann, M.L.; Ritzel, H.; Bergmann, L.; Hoelzer, D.; Mitrou, P.S. Reduced dose cladribine (2-CdA) plus mitoxantrone is effective in the treatment of mantle cell and low-grade non-Hodgkin's lymphoma. Eur. J. Cancer 2002, 38, 1739-1746.

201.Zinzani, P.L.; Magagnoli, M.; Bandandi, M.; Tani, M.; Stefoni, V.; Cellini, C.; Poggi, S.; Piccioli, M.; Pileri, S.; Tura, S. Long-term follow-up of hairy cell leukemia patients treated with 2chlorodeoxyadenosine. Haematologica 2000, 85, 922-925.

202. Hagenbeek, A.; Eghbali, H.; Monfardini, S.; Resegotti, E.; Hoskin, J.; de Wolf Peeters, C.; Mc Lennan, K.; Staab-Renner, E.; Schott, A.; Teodorovic, I.; Negrouk, A.; van Glabbeke, M.; Marcus, R. Fludarabine compared with CVP chemotherapy in newly diagnosed patients with stages III and IV low grade malignant non-Hodgkin's lymphoma . Blood 2001, 98, 843a (Abstract 3501).

203. Cabanillas, F. Purine nucleoside analogs in indolent non-Hodgkin's lymphoma. Oncology 2000, 14, 13-15.

204. Klasa, R.J.; Meyer, R.M.; Shustik, C.; Sawka, C.A.; Smith, A.; Guevin, R.; Maksymiuk, A.; Rubinger, M.; Samosh, M.; Laplante, S.; Grenier, J.F. Randomized phase III study of fludarabine phosphate versus cyclophosphamide, vincristine, and prednisone in patients with recurrent lowgrade non-Hodgkin's lymphoma previously treated with an alkylating agent or alkylatorcontaining regimen. J. Clin. Oncol. 2002, 20, 4649-4654.

205. Zinzani, P.L.; Stefoni, V.; Musuraca, G.; Tani, M.; Alinari, L.; Gabriele, A.; Marchi, E.; Pileri, S.; Bacarani, M. Fludarabine-containing chemotherapy as frontline treatment of nongastrointestinal mucosa-associated lymphoid tissue lymphoma. Cancer 2004, 100, 2190-2194.

206. Jäger, G.; Neumeister, P.; Brezinschek, R.; Hinterleitner, T.; Fiebiger, W.; Penz, M., Neumann, H,J.; Mlineritsch, B.; De Santis, M.; Quehenberger, F.; Chott, A.; Beham-Schmid, C.; Höfler, G.; Linkesch, W.; Raderer, M. Treatment of extranodal marginal zone B-cell lymphoma of mucosaassociated lymphoid tissue type with cladribine: a phase II study. J. Clin. Oncol. 2002, 20, 38723877.

207. Robak, T.; Lech-Maranda, E.; Janus, A.; Blonski, J.; Wierzbowska, A.; Gora-Tybor, J. Cladribine combined with cyclophosphamide and mitoxantrone is an active salvage therapy in advanced nonHodgkin's lymphoma. Leuk Lymphoma. 2007, 48, 1092-1101. 
208. Forstpointner, R.; Dreyling, M.; Repp, R.; Hermann, S.; Hänel, A.; Metzner, B.; Pott, C.; Hartmann, F.; Rothmann, F.; Rohrberg, R.; Böck, H.P.; Wandt, H.; Unterhalt, M.; Hiddemann, W.; German Low-Grade Lymphoma Study Group. The addition of rituximab to a combination of fludarabine, cyclophosphamide, mitoxantrone (FCM) significantly increases the response rate and prolongs survival as compared with FCM alone in patients with relapsed and refractory follicular and mantle cell lymphomas: results of a prospective randomized study of the German Low-Grade Lymphoma Study Group. Blood 2004, 104, 3064-3071.

209. Cohen, B.J.; Moskowitz, C.; Straus, D.; Noy, A.; Hedrick, E.; Zelenetz, A. Cyclophosphamide/fludarabine (CF) is active in the treatment of mantle cell lymphoma. Leuk Lymphoma 2001, 42, 1015-1022.

210. Thomas, D.W.; Owen, R.G.; Johnson, S.A.N.; Hillmen, P.; Seymour, J,F.; Wolf, M.M.; Rule, S.A.J. Superior quality and duration of response among patients with mantle cell lymphoma treated with fludarabine and cyclophosphamide with or without rituximab compared with prior responses to CHOP. Leuk. Lymphoma 2005, 46, 549-552.

211. Robak, T.; Smolewski, P.; Cebula, B.; Bloński, J.Z. Rituximab combined with cladribine or with cladribine and cyclophosphamide in heavily pretreated patients with indolent lymphoproliferative disorders and mantle cell lymphoma. Cancer 2006, 107, 1542-1550.

212. Saven, A.; Burian, C.; Kozioł, J.A.; Piro, L.D. Long-term follow-up of patients with hairy cell leukemia after cladribine treatment. Blood 1998, 92, 1918-1926.

213. Anaissie, E.J.; Kontoyiannis, D.P.; O’Brien, S.; Kantarjian, H.; Robertson, L.; Lerner, S.; Keating, M.J. Infections in patients with chronic lymphocytic leukemia treated with fludarabine. Ann.Intern. Med. 1998, 129, 559-566.

214. Van den Neste, E.; Delannoy, A.; Vandercam, B.; Bosly, A.; Ferrant, A.; Mineur, P.; Montfort, L.; Martiat, P.; Straetmans, N.; Filleul, B.; Michaux, J.L. Infectious complications after 2chlorodeoxyadenosine therapy. Eur. J. Haematol. 1996, 56, 235-240.

215. Samonis, G.; Kontoyiannis, D.P. Infectious complications of purine analog therapy. Curr. Opin. Infect. Dis. 2001, 14, 409-413.

216. O'Brien, S. Infections complications of nucleoside analogs. In Hematology; the American Society of Hematology: USA, 1999; pp. 536-542.

217. Anaissie, E.J.; Kontoyiannis, D.P.; O'Brien, S.; Kantarjian, H.; Robertson, L.; Lerner, S.; Keating, M.J. Infections in patients with chronic lymphocytic leukemia treated with fludarabine. Ann. Intern. Med. 1998, 129, 559-566.

218. Perkins, J.G.; Flynn, J.M.; Howard, R.S.; Byrd, J.C. Frequency and type of serious infections in fludarabine -refractory B-cell chronic lymphocytic leukemia and small lymphocytic lymphoma : implications for clinical trials in this patients population. Cancer 2002, 94, 2033-2039.

219. Cheson, B.D. Infectious and immunosuppressive complications of purine analog therapy. J. Clin. Oncol. 1995, 13, 2431-2448.

220. O'Brien, S.; Kantarjian, H.; Beran, M.; Koller, C.; Talpaz, M.; Lerner, S.; Keating, M.J. Fludarabine and granulocyte colony stimulating factor (G-CSF) in patients with chronic lymphocytic leukemia. Leukemia 1997, 11, 1631-1635.

221. Sudhoff, T.; Arning, M.; Schneider, W. Prophylactic strategies to meet infectious complications in fludarabine treated CLL. Leukemia 1997, 11, S38-S41. 
222. Byrd, J.C.; Hargis, J.B.; Kester, K.E.; Hospenthal, D.R.; Knutnson, S.W.; Diehl, L.F. Opportunistic pulmonary infections with fludarabine in previously treated patients with low-grade lymphoid malignancies: a role for Pneumocystic carini pneumonia prophylaxis. Am J, Hematol. 1995, 49, 135-142.

223. Samonis, G.; Kontoyiannis, D.P. Infections complications of purine analog therapy. Curr. Opinion Infect. Dis. 2001, 14, 409-413.

224. Mauro, F.R.; Foa, R.; Cerreti, R.; Giannarelli, D.; Coluzzi, S.; Mandelli, F.; Girreli, G. Autoimmune hemolytic anemia in chronic lymphocytic leukemia: clinical, therapeutic, and prognostic features. Blood 2000, 95, 2786-2792.

225. Kroft, S.H.; Tallman, M.S.; Shaw, J.M.; Thangavelu, M.; Peterson, L.C. Myelodysplasia following treatment of chronic lymphocytic leukemia (CLL) with 2-chlorodeoxyadenosine (2CdA). Leukemia 1997, 11, 170.

226. Van Den Neste, E.; Louviaux, I.; Michaux, J.L.; Delanoy, A. Michaux, L.; Hagemeijer, A.; Scheiff, J.M.; Bosly, A.; Stractmans, N.; Ferrant, A. Myelodysplastic syndrome with monosomy 5 and/or 7 following therapy with 2-chloro-2'-deoxyadenosine. Br. J.Haematol. 1999, 105, 268-270.

227. Robak, T. Second malignancies and Richter's syndrome in patients with chronic lymphocytic leukemia. Haematology 2004, 9, 387-400.

228. Cheson, B.D.; Vena, D.A.; Barrett, J.; Freidlin, B. Second malignancies as a consequence of nucleoside analog therapy for chronic lymphoid leukemias. J.Clin. Oncol. 1999, 17, 2454-2460.

229. Robak, T.; Błoński, J.Z.; Góra-Tybor, J.; Kasznicki, M.; Konopka, L.; Ceglarek, B.; Komarnicki, M.; Lewandowski, K.; Hellmann, A.; Lewandowski, K.; Moskwa, A.; Dmoszyńska, A.; Sokołowska, B.; Dwilewicz-Trojaczek, A.; Tomaszewska, A.; Sułek, K.; Całbecka, M. Second malignancies and Richter's syndrome in patients with chronic lymphocytic leukaemia treated with cladribine. Eur.J. Cancer 2004, 40, 383-389.

Sample availability: Not available.

(C) 2009 by the authors; licensee Molecular Diversity Preservation International, Basel, Switzerland. This article is an open-access article distributed under the terms and conditions of the Creative Commons Attribution license (http://creativecommons.org/licenses/by/3.0/). 